\title{
PRESENCIA INSTITUCIONAL DE RONCESVALLES EN BOLONIA (SIGLOS XIII-XVI)
}

\author{
POR
}

\author{
Pascual TamburRi Bariain
}

Universidad Pública de Navarra

\section{ResUmen}

A diferencia de otras naciones que enviaron estudiantes (principalmente juristas) a la Universidad de Bolonia desde los mismos orígenes de ésta, España dispuso de una institución asistencial consagrada en buena parte a sus escolares. La comunidad regular de Santa María de Roncesvalles, bien dotada de posesiones en todo occidente, alentó el desarrollo de la parroguia y hospital de Santa María de la Mascarelia con fines variados, pero en definitiva vinculados a la presencia continua de canónigos navarros y de otros espanfoles en el Estudjo italiano.

La documentación bolonesa utilizada en esta investigación aporta nuevos datos sobre esta institución navarra y sobre su evolución, y permite una mejor comprensión de una vinculación intelectual de considerable importancia para la España medieval

\begin{abstract}
Institutional presence of Roncesvalles in Bolonia XIII-XVIth centuries

Unlike other nations that sent their students (mainly jurists) to the University of Bologne since its origins, Spain had one institution largely devoted to its scholars. The Regular Community of St. Mary of Roncesvalles, well fumished of possessions in all the west, encouraged the development of the parish and hospital in St. Mary o via Mascarella, with variou purposes, anyway related to the continuous presence of navarrese canons and of other Spaniards in the Studium.

The Bolognese documents employed in this research bring new facts on this Navarrese institution and on its evolution, and allow a better understanding of an intellectual relationship remarkably imporlant for medjeval Spain.
\end{abstract}

Sobre la Iglesia Medieval Hispania Sacra 49 (1997) 
La participación de los navarros en el movimiento universitario medieval y, en general, la cuestión de los estudios a los que tuvieron acceso las minorías rectoras del reino en la época premodema, han ocupado un espacio nada desdeñable en la historiografía de las últimas décadas. Por una parte, ha interesado analizar las razones que impidieron una fundación universitaria estable en Navarra, a diferencia de otras regiones peninsulares. Por otra se ha tratado de analizar y explicar los movimientos de escolares y maestros hacia universidades y estudios dentro de la lógica de las instituciones a las que pertenecían o aspiraban a servir (monarquía, obispado, grandes fundaciones religiosas). Los datos así reunidos, de inapreciable utilidad para el investigador, deben sin embargo leerse a la luz de la realidad universitaria europea y española de cada época, de sus flujos intelectuales, su evolución institucional, sus circunstancias ocasionales e incluso sus modas.

Un capítulo no desconocido, pero tampoco adecuadamente valorado, de la vida cultural navarra en la Edad Media es la proyección universitaria de la comunidad regular de Santa María de Roncesvalles. Bien conocida desde recientes y brillantes investigaciones, la encomienda de Santa María «de la Mascarella» en la ciudad universitaria de Bolonia resulta ser, más que una inversión económicamente productiva, el eje de la preparación universitaria de los canónigos y, durante un período igualmente extenso, el punto de agregación de una floreciente comunidad científica hispana en Italia. La formación boloñesa de sus estudiantes situó por un tiempo a Roncesvalles y a Navarra a la cabeza de los reinos peninsulares, y sólo la decadencia de la pequeña encomienda dio paso a la preferencia por las facultades francesas.

\section{STUDIUM FUIT BONONIE. FUNDAMENTOS DEL PRESTIGIO DEL ESTUDIO BOLOÑES}

La destrucción de la fortaleza imperial en 1115 ha servido tradicionalmente para señalar el comienzo de la plena Edad Media en Bolonia ${ }^{1}$. Con el régimen consular que siguió a este hecho se consolidó el predominio de la nobleza. interesada, sí, en la defensa de las libertades municipales, pero mucho más en el reforzamiento de su propio poder social y político. En torno a la lucha que este proyecto genera giran los dos siguientes siglos de historia local.

Pero ya a comienzos del siglo XII Bolonia era conocida sobre todo por su Estudio. No nos compete aquí analizar el nacimiento de éste, pero conviene recordar que aquella ciudad debio su fortuna intelectual a la presencia de maestros formados en la tradición jurídica justinianea, en su momento en el

I FASOLI, G., Bologna nell' etò medievale (1155-1506), en FERRI, A., y ROvERSI,.G., dir., Storia di Bologna, Bologna, 1978, pp. 134 y ss. 
que toda Europa empezaba a sentir interés por el Derecho romano. Pepón, primero, y, sobre todo, Imerio y sus discípulos (los famosos «cuatro doctores»), dieron forma estable a las escuelas que habían de ser causa de la grandeza de la ciudad ${ }^{2}$. Poco importa, así, que la fecha de 1088 sea algo más que un mito del idealismo decimonónico); en ese arco o muy poco después, numerosos estudiantes, italianos o no, estudiaban ya junto al Reno unas leyes que, aunque no aplicadas ni aplicables, eran fundamento de una renovación generalizada de la vida cultural y jurídica.

Sin competencia en esto durante un siglo largo, Bolonia ofrecía una novedad intelectual absoluta, y vio formarse en torno a las escuelas numerosas comunidades de estudiantes extranjeros, estímulo directo para la economía urbana. Pese a sus relaciones equívocas con Federico I, Bolonia se consolidó como potencia territorial en el área padana, y políticamente fue capaz de oponerse con éxito en su propio ámbito al proyecto imperial de Federico II, una generación después y tras una evolución política que supuso el nacimiento del $\mathrm{Co}$ mune popular y la decadencia de las grandes familias ${ }^{3}$.

El Estudio no tuvo nunca una vida independiente de la de la ciudad como no podía ser de otra forma. Dependiente de poderes externos (el Papa, el Emperador, la ciudad, los obispos y el alto clero), la institución universitaria pasó también por una fase «aristocrática» en su organización, con el predominio de los doctores garantizado por Barbarroja, para pasar después a un momento «comunal» que caracteriza, en definitiva, al que se ha dado en llamar «modelo bolonés» de Universidad. Este «modelo», reconocible por el poder de las corporaciones de estudiantes, tuvo su crisis en el siglo XIV y desapareció. Sólo teniendo presente esta evolución interna y externa puede comprenderse la evolución de la presencia y actividad de los estudiantes medievales españoles en Bolonia, en general, y, en particular, las de los navarros 4 .

La formación del Estudio fue, pues, anterior en más de un siglo a la constitución de las Universitates y, por lo tanto al surgimiento de un tipo de Uni-

2 VERGER, J., Le Università nel Medioevo, Bologna, 1993, pp. 38 y ss.; ibidem, p. 56; DOLCINI, C., Pepo, Imerio, Graziano. Alle origini dello «Studium* di Bologna, en CAPITANi, O., dir., L'Università a Bologna. Personaggi, momenti e luoghi dalle Origini al XVI secolo, Milano, 1997, pp. 17 y ss., asi como, siguiendo criterios ya superados pero con datos todavía interesantes, FITTING, H., Pepo zu Bologna, «Zeitschrift der Savigny - Stiftung für Rechtsgeschichte», 23, 1902. pp. 31-45.

${ }^{3}$ FASOLJ, G., Bologna, pp. 143 y ss.

4 SORBElLI, A., Storia dell'Universitc̀ di Bologna, Volume I, Il Medioevo (sec. XI-XV), Bologna, 1940, pp. 20 y ss.; acerca de las primeras noticias sobre las nationes ultramontanas como forma característica del asociacionismo estudiantil bolonés. Véase SORBELLI, A., La *Nazione» nelle antiche Università italiane e straniere, «Studi e memorie per la storia dell'Università di Bolognan, 16, Bologna, 1943, pp. 112 y ss. 
versidad peculiarmente boloñés . Estos primeros pasos organizativos y el proceso evolutivo que llevó al predominio de los scholares y la estructura corporativa y nacional característica del «modelo» han sido estudiados con gran acierto y no es nuestro objetivo en este caso describirlos ${ }^{6}$. El Studium fue desde el principio el resultado de una coincidencia de intereses, basado en la dependencia (subiectio) del estudiante respecto al doctor, similar a la situación de los aprendices, salvando las distancias; en realidad, la Universidad en su conjunto tuvo siempre muchos puntos de contacto con las corporaciones profesionales coetáneas? ${ }^{7}$ La constitución imperial (de Federico I) Autentica «Habita» fue una consagración, por una parte, de la autonomía universitaria frente a los poderes exteriores, y, por otra, una sanción del poder de los doctores sobre sus alumnos ${ }^{8}$.

Los ciento cincuenta años que siguieron implicaron tensiones paralelas en la ciudad y en la Universidad. En 1257, tras librarse definitivamente del dominio imperial Bolonia decretó la libertad de los siervos, para después, en un momento de esplendor demográfico y económico, enzarzarse en una clásica y desangrante lucha entre los dos partidos patricios, Lambertazzi y Geremei, que culminó en la guerra civil de 1274 a 1299. Simultáneamente, el Studium asistió a su máxima expansión en todos los órdenes, vivió su internacionalización y padeció una radical transformación interna consistente en su gestión directa no ya por los maestros sino por los estudiantes agrupados por sus orígenes, y todo ello con luchas a veces sangrientas. En este contexto debe encuadrarse la llegada de los primeros navarros, su inserción junto a los demás españoles y la consolidación de su institución peculiar: el hospital y parroquia de la Mascarella $a^{9}$.

5 BRIzZl, G. P., y PIN], A. l., Prefazione, en BRIzz], G. P., y PIN], A. I., Studenti e Universitd degli studenti a Bologna dal XII al XIX secolo, «Studi e memorie per la storia dell'Università di Bologna", n.s., VII, Bologna, 1988, p. 7; y HALPHEN, L., Les universités au XIJ siècle, in $\dot{A}$ traver,s l'Histoire du Moyen Age, Paris, 1950, p. 305

6 Valga por todas la síntesis de Sven STELLING-MICHAUD, L'Université de Bologne et la pénétration des droits romain et canonique en Suisse aux XIIÌ et XN siècles, Genève, 1955, pp. 13-75.

${ }^{7}$ GRECI, R., L'associazionismo degli studenti dalle origini alla fine del XN secolo, en BRIZZI, G. P., y PINI, A. I., Studenti, p. 18; BELLOMO, M., Saggio sull'Università nell' età del Dirito comune, Catania, 1979, p. 17; y PIN1, A. I., aDiscere turba volens». Studenti e vita studentesca a Bologna dalle origini dello Studio alla metd del Trecento, en BRIzZI, G. P.., y PINI, A. I., Studenti, pp. 54 y ss. CALASSO, P., Gli ordinamenti gitridici del rinascimento medievale, Milano, 1965, pp. 93 y ss., 132 y ss., sobre las analogías entre los gremios y el Studium.

Sobre las variadas interpretaciones que se han dado a este conocido documento imperial, véase GRECI, R. L'associazionismo, pp. 25 y ss., y STELZER, W., Zum Scholaren-privileg Friedrich Barbarossa («Authentica "Habita" "), «Deutsches Archiv für Erfoschung des Mittelalters», 34, 1978, pp. 123-165, que resumen las conclusiones de un largo debate historiografico.

${ }^{9}$ FASOLI, G., Bologna, pp. 154 y ss. 


\section{EL MOVIMIENTO UNIVERSITARIO EN ESPAÑA. NAVARRA}

No es posible hallar pruebas de una relación cultural entre Bolonia y España antes del siglo XII y, en cualquier caso, antes de la fundación del Estudio General; todo intento en ese sentido está condenado a caer en lo anecdótico o, peor, en lo mítico ${ }^{10}$. El Derecho común no fue conocido en ninguna parte de España antes de 1100 , e incluso más tarde, y ciertamente no era ni Derecho aplicable ni fuente inspiradora del mismo. Sin embargo, la apertura generalizada a las corrientes eclesiásticas, culturales y jurídicas ultrapirenaicas, que en Castilla arranca de Alfonso VII y que tiene sus equivalentes en otros espacios políticos, permitió la recepción de la obra justinianea y la formación de los primeros universitarios hispanos ${ }^{\prime 1}$.

La acción de los reyes, la de los papas y el prestigio de las Universidades hizo el resto. Las monarquias quisieron dar a sus hombres de letras y de gobierno una cultura jurídica acorde a las nuevas tendencias, y Castilla patrocino, aunque tímidamente, el primer intento universitario en Palencia. Aunque el intento no cuajó adecuadamente, es un claro signo de una política cultural de todos los reinos hispanos en este momento. Sin embargo, los tiempos no estaban maduros para un proyecto semejante, y los universitarios hispanos, progresivamente más numerosos, debían acudir a instituciones francesas o italianas. En particular, conviene recordar que italiano fue Ugolino da Sesso ${ }^{12}$, que enseñó Derecho Civil en Palencia, en tomo a 1178, y que Jacopo Giunta, llamado en Castilla Jacobo de las Leyes, contemporáneo y consejero de Alfonso $\mathrm{X}$, contribuyo ciertamente a la preparación de las Partidas ${ }^{13}$.

La cultura universitaria española tuvo, como se puede ver, un marcado carácter italiano desde su mismo origen, y esto sólo puede deberse a una presencia precoz y continuada de hispanos en el Alma Mater boloñesa. Centro privilegiado de la renovación jurídica, incluso antes de que existiesen centros universitarios en España, Bolonia acogió, primero a estudiantes juristas, y más tarde también a maestros de todos los reinos cristianos. Esta tradición se mantuvo incluso cuando ya se habían fundado en ellos las primeras universidades

10 MESINI, C., Gli spagnoli a Bologna prima della fondazione del Collegio di Egidio di Albornoz (1364-1369), «Studia Albornotiana», XII, «EI cardenal Albomoz y el Colegio de España», II, Bolonia, 1973, pp. 45 y ss. Más equilibrado GARCía Y GARCÍA, A., El Studium bononiense y la Peninsula Ibérica, en GaRCía Y García, A., Iglesia, Sociedad y Derecho, Salamanca, 1985, pp. 45 y ss.

"G GarCía Y GARCía, A., La penetración del Derecho clásico medieval en España, «Anuario de Historia del Derecho Espaílol», 36, Madrid, 1966, p. 575; y CaLASSO, F., Medio Evo del Diritto. Milano, 1954, passim.

12 GARCIA Y GARCía, A., En torno al Derecho romano en la España medieval, en GaRcía Y García, A., Iglesia, p. 69.

13 Garcia y García, A., El Studium, p. 55. 
estables, y hasta muy avanzado el siglo XIV el flujo de futuros juristas hacia Bolonia, como el de futuros artistas, téblogos y médicos hacia Francia, fue cuantitativamente importante, y cualitativamente trascendente. Para los navarros que deseasen una preparación adecuada en ambos Derechos s6́lo quedaba abierta la vía de Italia, porque Francia no podía ofrecer un nivel académico equivalente en este terreno. Precedidos por estudiantes inquietos que acudieron aislados, pronto contingentes organizados siguieron ese camino; como en el caso de Roncesvalles, la formación jurídica adecuada era cada vez más, ya a finales del siglo XII, una necesidad administrativa y canónica de las grandes instituciones del Reino ${ }^{14}$.

\section{HISTORIA INTERNA DE RONCESVALLES. DOCUMENTACIÓN}

Los recientes trabajos de là doctora $\mathbf{E}$. Ramírez Vaquero y, sobre todo, del doctor F. Miranda García, muestran bajo nueva luz los aspectos formales y patrimoniales de la gran fundación pirenaica, cuya importancia nunca había sido totalmente olvidada, pero tampoco suficientemente resaltada ${ }^{15}$. La historia de Roncesvalles aparece marcada por dos preocupaciones constantes, como son, por una parte, la gestión del patrimonio y, por otra, la organización interna. La renovación intelectual no podía no repercutir directamente en ambos, y, de un modo indirecto, en todo lo que dependía de la comunidad regular, como sus encomiendas dispersas por Europa.

Aunque no se conoce la fecha exacta de fundación, parece que la vida comunitaria empezó en Roncesvalles antes de mediado el siglo XII, dependiendo del obispado de Pamplona y bajo la regla de S. Agustín. Sólo en 1217, sin embargo, se llegó a una autonomía completa de Pamplona, al asumir Honorio III el patronato ${ }^{16}$. La elaboración por parte de F. Miranda de un modelo explicativo del desarrollo y contracción del patrimonio de Roncesvalles ha proporcionado también nuevas ideas para el estudio de las encomiendas extrapeninsulares, cuyo origen es muy poco posterior al del propio gran centro pirenai-

14 GaRCIA y García, A., La penetración..., p. 579.

I5 IBARRA, J., Historia de Roncesvalles, Pamplona, 1935; se sirve de una historia de la encomienda de Roncesvalles escrita por Giovanni Barcini en Época modema y conservada en la Colegiata; pero sus noticias no son de primera mano y, en ocasiones, resultan gravemente inexactas.

3 RAMírez VAQUERo, E., La comunidad regular de Santa Maria de Roncesvalles (siglos XIXIX), «Príncipe de Viana*, 54, Pamplona, 1993, p. 359; CALZONI, F., Storia della chiesa parrocchiale di Santa Maria in via Mascarella e dei luoghi più cospicui che si trovano nella di lei giurisdizione; $i$ quali sono l'ospitale di S. Onofrio unito all'arciconfraternita di S. Maria Maddalena, la confraternita della B. Vergine del Soccorso detta del Borgo di S. Pietro, il monastero di S. Guglielmo e il collegio Ferrerio detto della Viola, compilata da..., Bologna, 1785, p. 8.

Sobre la Iglesia Medieval Hispania Sacra 49 (1997) 
$\operatorname{col}^{17}$. Por lo que se refiere a la Mascarella, la documentación conservada en la Colegiata no permite más que una primera aproximación, ya que el mayor volumen documental está en los archivos italianos.

En todo caso, incluso teniendo en cuenta las limitaciones que la carencia de fuentes ha impuesto a los historiadores navarros, puede darse como cierto que el patrimonio exterior de Roncesvalles aumento extraordinariamente entre los siglos XII y XIII, que ese crecimiento hizo imposible la dependencia institucional de la mitra de Pamplona y dio lugar a la plena autonomía estatutariamente establecida, y que la encomienda italiana fue de las primeras en formarse y consolidarse. Nacido para asistir a los peregrinos, Roncesvalles tuvo en ellos su más eficaz propaganda, el origen de numerosas donaciones y los cimientos de nuevas fundaciones, que sin embargo nunca ocultaron su carácter esencialmente navarro ${ }^{18}$.

En este marco general, Ja documentación italiana permite trazar una histona pormenorizada de la Mascarella y precisar, entre otras cosas, que su origen la coloca entre las más antiguas posesiones de la Colegiata, probablemente no posterior a la encomienda de Goalard, en Armagnac, en $116^{19}$. En estas páginas se hará amplio uso de los documentos conservados en Italia, particularmente aquellos que, por su naturaleza iusprivatística, han permanecido ignorados hasta ahora, como la serie de registros de los Memoriales («Memoriali»), en los que se recogen todas las transacciones superiores a las veinte libras boloñesas. Las noticias de ese origen, junto a la documentación conocida y publicada en España y a los estudios tanto españoles como italianos, proporcionan un nuevo y sugestivo cuadro para una de las instituciones navarras más singulares de toda la Edad Media.

Tanto los primeros Estatutos de Roncesvalles como, sobre todo, los segundos, vigentes desde $1287^{20}$, organizan en sus líneas generales el funcionamiento de las encomiendas y bienes excéntricos respecto al núcleo pirenaico. Dos canónigos, de los setenta y dos previstos, tenđrían la función de visitadores itinerantes de todas las dependencias de la Colegiata; un comendador, no necesariamente canónigo, se habría de establecer en Bolonia, con competencias sobre toda Italia y amplia libertad para reclutar personal y gestionar el patrimonio: unas normas en las que es evidente el peso de la experiencia ${ }^{21}$, por más que la escasez documental (sólo un documento de esta época -1272- con-

17 MIRANDA GarCiA, F., Roncesvalles. Trayectoria patrimonial (siglos Xn-XIX). Pamplona, 1993.

18 Miranda Garcia, F., Roncesvalles, p. 258.

19 Miranda Garcia, F, Roncesvalles, pp 95-96 y 259; véase et. inf.

20 Publicados íntegramente por OstolazA El.1ZONDO, M. I., Colección, n. 301, pp. 385-393.

21 RAMÍREZ VAQUERO, E., La comunidad, p. 370; MIRANDA GARCÍA, F., Roncesvalles, p. 97 y ss. 
servado en Roncesvalles ${ }^{22}$ ) pudiera hacer pensar en una lánguida vida de la encomienda italiana. En la centuria siguiente, en cambio, decreció el peso específico de la Mascarella en el seno de una comunidad regular dividida y empobrecida, pero la información disponible en Navarra es algo más rica ${ }^{23}$.

A pesar de la profunda renovación del conocimiento de la historia de Roncesvalles, queda mucho por hacer en cuanto a las encomiendas periféricas, $y$, sobre todo, por lo que se refiere a Bolonia. Una documentación italiana abundante, pero anárquicamente utilizada y nunca recogida en su integridad hasta ahora, puede ofrecer nuevas luces para la historia del hospital italiano e, incluso, marcar las etapas de la expansión extrapeninsular de la Colegiata. Curiosamente, de toda la bibliografia italiana relativa de un modo u otro, a la Mascarella, la única obra generalmente consultada en España la de F. Guidicini, por muchas razones superada, mientras que son generalmente ignoradas las dos historias de la Mascarella, publicadas en los siglos XVIII y $\mathrm{XX}^{24}$, ricas en referencias documentales e inmediatamente posterior, la segunda de ellas, a la destrucción de la venerable parroquia y del anejo hospital en 1943.

\section{FORMACIÓN DE LA ENCOMIENDA ITALIANA: LA MASCARELLA}

La encomienda boloñesa siguió en todo la parábola ascendente (hasta el siglo XIV) y descendente (a continuación) de la institución matriz ${ }^{25}$. Cuando la debilidad y desidia de Roncesvalles hizo imposible aquella dependencia, la Mascarella pasó a ser puramente boloñesa y dejó de cumplir las múltiples misiones a que se había dedicado durante su etapa española.

Como ya había concluido el padre Calzoni en el siglo XVIII, lo único cierto sobre el arranque de la presencia de Roncesvalles en Italia es que nunca llegaremos a conocer la fecha exacta; probablemente la segunda mitad del siglo XII.

22 Véase IBARRA, J., Historia, p. 144; OSTOlaZA ELIZONDO, M. I., Colección diplomatica de Santa Maria de Roncesvalles (1127-1300), Pamplona, 1978, p. 315, doc. 234 (A-ACR, Bulas, faxo $\left.1^{\circ}, n^{\circ} 58\right)$.

${ }^{23}$ Martinena Ruiz, J. J., Catalogo documental de la Real Colegiata de Roncesvalles (13011500), Pamplona, 1979.

24 GUIDICINI, G., Cose notablli della città di Bologna ossia Storia cronologica de' suoi stabili sacri, pubblici e privati, per..., pubblicata dal figlio Fernando e dedicata al municipio di Bologna, IV, Bologna, 1870; CAlzoNI, F., Storia; FoRNASINI, G., La chiesa priorale e parrocchiale di S. Maria e S. Domenico detta della Mascarella, Bologna, 1943; en general, SoRBELLl, A., Storia dell' Universitd di Bologna, I, II Medioevo (sec. XI-XV), Bologna, 1940, passim.

25 Il nome della strada è spiegato in FANTI, M., Le vie di Bologna. Saggio di toponomastica storica e di storia della toponomastica urbana. Opera promossa dal Comune di Bologna. Bologna, 1974, pp. 451 y ss. 
No es posible establecer el año de nacimiento de la parroquia de Santa María «in vía Mascarella» ni el mecanismo jurídico que tan sólidamente la ligó a la lejana comunidad española, y en esto ni siquiera la advocación elegida o referencias documentales indirectas son de ninguna utilidad contrariamente a otros $\operatorname{casos}^{26}$.

La cuestión de los orígenes de la Mascarella plantea dos problemas que exigen un tratamiento independiente: por un lado, la fundación de la parroquia italiana y, por otro, su dependencia de Navarra. Es cierto que, en general, se ha afirmado que la iglesia boloñesa fue fundación directa de los canónigos regulares de Roncesvalles, primero como hospital y después como parroquia en la zona nororiental de Bolonia ${ }^{27}$. Sabemos, sí, que antes de 1241 un obispo $\mathrm{Ge}$ rardo fijó los límites de las jurisdicciones parroquiales urbanas y suburbanas, y que en esa tesitura aparece la Mascarella ${ }^{28}$. Ahora bien, mientras que Gerardo de Gisla fue obispo en la ciudad petroniana del 1187 al 1198, Gerardo degli Ariosti le sucedió hasta el 1213. La iglesia de la Mascarella existiría ya, pues, con seguridad, entre estas fechas extremas, justo fuera del segundo recinto amurallado de la ciudad y con una amplia parroquia extramuros.

Ibarra transmite la fecha más antigua de las posibles -1170 - recogida en la crónica de Barcini, y otros le siguen en esto, ya que la cuestión no ha preocupado a nadie. Durante el episcopado de Gerardo Gisla se construyó un segundo cinturón medieval de murallas (1176), así como el canal del.Reno, y por estos datos resulta más probable la fecha más alejada para datar la toma de posesión de Roncesvalles sobre la Mascarella, ya que en el documento de límites arriba mencionado se hacen referencias explícitas a las nuevas murallas.

Dejando abiertas ambas posibilidades, queda por aclarar una cuestión esencial. Para demostrar que la iglesia de la Mascarella fue fundada directamente por Roncesvalles no hay otras pruebas que la opinión de cronistas muy posteriores en el tiempo y las analogías con otras fundaciones hechas en la misma época en Bolonia ${ }^{29}$. La posición de la encomienda boloñesa no se casa fácilmente con la finalidad económica propia de otras fundaciones de Roncesvalles, ni tampoco con su actividad asistencial, por encontrarse en la periferia de una ciudad en

${ }^{26}$ CALZONI, F., Storia, pp. 5 y ss.

${ }^{27} \mathrm{PINI}$ A. I., Le ripartizioni territoriali urbane di Bologna Medievale. Quartiere, contrada, borgo, morello, quartirolo, «Quaderni culturali bolognesi», 1, Bologna, 1977, pp. 1-50.

${ }^{28}$ Catálogo documental de Santa María Mascarella [Apéndice], n. 1.

29 CALzoni, F., Storia, pp. 6-7. 
constante expansión por la presencia siempre problemática de estudiantes extranjeros (necesitados por lo demás de auxilios espirituales y materiales) ${ }^{30}$.

Contrariamente a la tradición tantas veces repetida, y muy de acuerdo con la historia de tantas fundaciones religiosas de la época, incluidas otras encomiendas de Roncesvalles, parece más probable que la parroquia existiese ya, verosímilmente desde el siglo XII, y que Roncesvalles la adquiriese muy a principios del XIII (cuando, como vamos a ver, se documenta su funcionamiento en los orígenes mismos de la Orden dominica). La repentina aparición en el corazón de Italia de una parroquia, un hospital y sus bienes anejos, dependientes de una institución española, se explica mejor por una compra o una donación cuando el complejo ya estaba en funcionamiento, aunque fuese desde muy pocos años antes ${ }^{31}$. Pero ésta no deja de ser una suposición, aunque avalada por la sospecha (F. Miranda) de que Roncesvalles adquirió por compra buena parte de sus bienes ultrapirenaicos, con fines específicos en cada caso.

Sea como fuere, fundación o más bien adquisición, donación o más bien compra, lo cierto es que Roncesvalles estaba ya en Bolonia en torno al 1200. En el contexto general de la institución, esta fecha significa un notable anticipo respecto al gran despliegue patrimonial y económico de los años centrales del $\mathrm{XIII}^{32}$. No sólo; la documentación boloñesa que aquí se maneja permite adelantar casi un siglo el inicio del funcionamiento de la encomienda, que las fuentes españolas no llevaban más allá de los años setenta del siglo ${ }^{33}$.

¿Qué utilidad tenía para Roncesvalles un hospital-parroquia en Bolonia? Los objetivos que el cabildo de Roncesvalles tuviese al fundar y/o mantener una encomienda en Bolonia marcan decisivamente el carácter de la Mascarella y pueden servir para explicar algunos aspectos peor conocidos de la historia de ésta.

En primer término, como todas las propiedades, encomiendas, derechos y fundaciones relacionados con Roncesvalles, el destino de la Mascarella era la rentabilidad, cifrada, en primer lugar, en la autosuficiencia, y después en sus remesas a la comunidad titular ${ }^{34}$. Aunque pocas instituciones eclesiásticas medievales españolas tuvieron un radio de acción mayor, el volumen global de

${ }^{30}$ MiRAnda GaRCía, F., Roncesvalles, pp. 95-96; sobre el proceso en general, PinI, A. I., Pro. blemi di demografia bolognese del Duecento, «Atti e Memorie della Deputazione di Storia Patria per l'Emilia e la Romagna», n.s., 17, Bologna, 1969, pp. 147-222.

31 MIRANDA García, F., Roncesvalles, p. 90. Como es sabido, Roncesvalles, además de en Bolonia, tuvo encomiendas y rentas en buena parte de la España cristiana, incluyendo Portugal, en Francia, en Inglaterra y en Gales.

32 Miranda García, F., Roncesvalles, p. 97.

33 MiRANDA GARCIA, F., Roncesvalles, p. 259. De 1272, para mayor precisión.

34 Calzoni, F., Storia, p. 9. 
la actividad económica no siempre respondió a lo deseado, sobre todo cuando, a partir de finales del siglo XII, los costes de gestión superaron los ingresos producidos por buena parte del patrimonio disperso. En el caso concreto de la Mascarella, hubo probablemente un cierto superávit hasta entrado el siglo XIV, del que son testimonio algunos envíos en metálico a Navarra. No obstante, es cierto que los bienes situados en Bolonia no bastaban ni en el mejor de los casos para generar sumas relevantes, y que la relativa riqueza de la encomienda pudo deberse más bien a cuestaciones y limosnas extraordinarias. Más adelante, la Mascarella requería aportaciones de Roncesvalles, lo que condujo a su gestión indirecta.

Vemos, pues, que las condiciones del complejo bolonés no se corresponden con unas metas exclusiva o prevalentemente económicas. Otras encomiendas de Roncesvalles (Bar-sur-Seine en Champaña y Villefranche-sur-Saone en Borgoña) tuvieron también hospitales que, como la Mascarelła, extendieron por Europa la tarea asistencial peculiar de la Colegiata y que, igualmente, tenían una rentabilidad más caritativa que financiera. La Mascarella siempre mantuvo un hospital, y esta actividad, bajo una u otra forma, duró más que la propia dependencia de la institución española.

En tercer lugar, Santa María de la Mascarella tuvo una funcí́n universitaria que explica y complementa las dos anteriores. Casi desde su fundación, la Mascarella recibió Jimosnas y donativos para ayudar a los pauperes extranjeros venidos a la ciudad; como en un ejemplo de 1343, en palabras de un gran benefactor del hospital

\footnotetext{
«...pro ut sibi videbitur in quo perpetuo debeant educari, hospitari et gubernari pelegrini pauperes et egri pauperes, pro salute anime ipsius.... ${ }^{35}$
}

Ahora bien, no se trata aquí de una común actividad asistencial, sino de una específica actividad universitaria, ya que, en la Bolonia del siglo XIV, y con más razón en el anterior, los extranjeros pobres eran por definición los escolares ultramontanos (algunos de ellos, al menos). En esto, la Mascarella parece tener una amplia autonomía operativa de Roncesvalles, ya que recibe directamente los donativos, y un programa de ayuda que se basa en alojar, educar y someter a disciplina a los estudiantes. Si se observan los desórdenes de la vida de los estudiantes en los primeros siglos de Universidad (y también después), no puede sorprender el programa que se nos da en 1343 de la Mascarella, cuya vocación específica es sin duda la Universidad.

35 Catálogo documental de Santa María Mascarella [Apéndice], n. 17; CALZoNI, F., Storia, p, 26. 
No es nueva la hipótesis según la cual la Mascarella habría servido sistemáticamente para proporcionar alojamiento a canónigos de Roncesvalles que acudían al Estudio ${ }^{36}$. Estos mismos canónigos, que no fueron los ni únicos estudiantes ni los únicos navarros en el hospital, tuvieron un papel fundamental en la gestión de la encomienda. Incluso cuando Roncesvalles perdió la gestión de la Mascarella, conservó el derecho de mantener allí alojado algún canónigo, facultad a la que el Cabildo se aferró tenazmente. Roncesvalles nunca tuvo una escuela propia para formar teólogos y canonistas, pero, al enviar sistemáticamente a la Mascarella a sus canónigos, con frecuencia como comendadores, podía acceder de manera privilegiada a estudios entre los más prestigiosos (aunque en Bolonia no se enseñó Teología hasta el gobierno del cardenal Albornoz) ${ }^{37}$. De esta finalidad de la fundación son evidencia algunos testimonios documentales, de los que arranca la sospecha que avanzó en su momento F. Miranda, según la cual la Mascarella habría servido también para alojar canónigos estudiantes! invirtiendo ahora los términos, pođemos decir que esa función fue la principal, al menos durante largas fases. Esta hipótesis, para la que encontramos confirmación suficiente en la documentación boloñesa, se complementa perfectamente con las intuiciones del doctor F. Miranda, que ve en buena parte de la red de posesiones de Roncesvalles fuera de España una intención primaria o secundariamente universitaria ${ }^{38}$.

Aunque todavía sea posible discutir sobre la pluralidad de usos que Roncesvalles dio a la Mascarella, y por más que no sea posible aclarar ulteriormente el proceso de fundación de la encomienda, es seguro que ya a finales del siglo XII existía la parroquia de Santa María de la Presentación de la Mascarella en Bolonia, perfectamente delimitada y con ciertas rentas, y que entonces o muy poco después Roncesvalles la gestionaba, asignándole ya sus funciones peculiares. El siglo XIII fue de verdadero despegue organizativo y patrimonial, y en él se definieron claramente las funciones de la encomienda, como vamos a ver.

\section{LOS DOMINICOS EN LA MASCARELLA}

Por evidentes razones de solidaridad, los españoles que durante la Edad Media estudiaron en Bolonia mostraron una fortísima tendencia a asociarse y a convivir, como sin duda aconsejaban las peculiaridades organizativas del Estudio y los sobresaltos de la vida en las ciudades italianas. Esta tendencia a

\footnotetext{
36 Guidicini, G., Cose, p. 202.

37 GOÑI-GAZTAMBIDE, J., La formación intelectual de los navarros en la Edad Media (II221500), «Estudios de Edad Media de la Corona de Aragón», 10, Zaragoza, 1975, pp 152-153.

38 F. MiRanda GaRCía, Roncesvalles, p. 259.
} 
agruparse puede extenderse a las instituciones españolas o con presencia de españoles, prescindiendo del reino o región de que cada uno proviniese. En el caso de la Mascarella, la primera y mejor prueba de esta apertura es la estancia en el hospital del primer grupo de dominicos en Bolonia compuesto por españoles y dirigido por el mismo Santo fundador.

En 1218, fecha en la que, sin duda, la Mascarella tenía ya su forma institucional bien definida como encomienda, hospital y parroquia de Roncesvalles, sirvió como base para la primera predicación de los dominicos en Italia, y en particular en el ámbito universitario que siempre fue su preferido ${ }^{39}$. Completamente integrados en la vida universitaria de la ciudad, los primeros éxitos de los dominicos fueron precisamente dentro de la comunidad de estudiantes hispanos y desde el hospital navarro.

En principio, la estancia de los dominicos en la Mascarella pudo ser vista con interés también desde Roncesvalles, ya que la mayor presencia española debía contribuir, sin duda, a mejorar la gestión de la encomienda, siempre difícil por la lejanía y el aislamiento del comendador. Santo Domingo llegó a Bolonia. a comienzos de 1218, con fray Miguel de Ucero y fray Domingo, ambos, como él, canónigos de Osma. Poco después, el Fundador marchó a Roma, para obtener la aprobación pontificia definitiva, dejando en la ciudad a sus discípulos con el encargo de predicar y de seguir viviendo en el hospital de la Mascarella, que les había servido de primer refugio ${ }^{40}$. El hospital navarro fue, pues. la primera base estable de la predicación de los dominicos en Italia.

En abril del mismo año llegaron otros dos hermanos españoles, fray Beltrán Garrigues y fray Juan de Navarra, que formaron junto a los anteriores la primera comunidad. Sin embargo, sus progresos fueron escasos, y de estos meses sólo se conoce por testimonio muy dudosos la profesión de un cierto fray Ricardo, que según la tradición de la Orden habría sido canónigo de Roncesvalles en la Mascarella. De esto último no hay testimonios documentaies, aunque sí se conoce la existencia de un español de nombre Ricardo entre los frailes en años sucesivos. Sea como fuere, a estos cuatro o cinco españoles, de los cuales uno o dos navarros, se unieron en Bolonia, antes del verano fray Cristiano y

39 Calzoni, F., Storia, p. 10; IBARRA, J., Historia, pp. 138-143, con un resumen de la presencia de los dominicos en la Mascarella; en general, D'AMATO, A., I domenicani e I'Università di Bologna, Bologna, 1988, con todos los detalles conocidos, incluyendo algunos evidentemente legendarios, sobre el establecimiento y los primeros pasos de los frailes en Bolonia. Nos remilimos a LIPPINl, P., Sulle orme del Padre. Bologna, 1985, para todo lo referido al arranque de la vida religiosa dominicana en la ciudad, que sólo tratamos aquí en los que se refiere a la Mascarella y a los estudiantes espafioles; D'AMATo, A., L'Ordine dei Frati Predicatori. Carisma, storia, attualita, Roma, 1983; D'AMATO, A., I domenicani a Bologna, I, 1218-1600, Bologna, 1988. Vease también MESINI, C., Gli spagnoli, p. 53.

40 CAlzoni, F., Storia, p. 10; IBARRA, J., Historia, pp. 138-143. 
fray Pedro Converso, ambos estudiantes españoles que habían sido ganados en Francia por la predicación de los mendicantes ${ }^{41}$.

El verdadero despliegue proselitista y organizativo de los dominicos tuvo lugar a partir de la llegada, el 21 de diciembre de 1218, de fray Reginaldo de Orléans, que dirigió todos los esfuerzos de la pequeña comunidad a la predicacion entre los estudiantes, sobre todo espanoles y franceses. Fray Reginaldo era un hombre muy experimentado en la vida universitaria, además de un organizador muy eficaz. Al poco de llegar, fue nombrado por santo Domingo vicario para Italia, en un momento en el que la presencia de la Orden en aquella península estaba prácticamente limitada al convento precariamente instalado en la Mascarella ${ }^{42}$.

Gracias al trabajo y a la dirección de su discípulo francés, santo Domingo, al regresar a Bolonia en agosto de 1219, encontró una comunidad floreciente, respetada y bien conocida en la ciudad y en la Universidad. Según la tradición, predicó personalmente e hizo numerosos milagros, que fundamentaron la posterior devoción por él y por su obra ${ }^{43}$. Sabemos, sobre estos meses, que santo Domingo tuvo como discípulo directo a un estudiante español de Derecho civil, conocido después como fray Esteban de España, que profesó como dominico en el mismo año de 1219 , fue nombrado maestro provincial de la Lombardía y, años después, fue testigo en el proceso de canonización del santo español ${ }^{44}$. Centrada en la Mascarella, la primera predicación de los dominicos en Italia tuvo, como se puede ver, un marcado sesgo español y universitario.

Se ha llegado a afirmar, partiendo de una comprensión apresurada de algunas afirmaciones equívocas del fundamental testimonio de F. Calzoni, que la Mascarella fue en este momento propiedad de los dominicos, y que sólo después de la consolidación de éstos el Obispo asignó el hospital y la parroquia a Roncesvalles. Sin embargo, lo único seguro sobre la presencia de Roncesvalles en la Mascarella es, precisamente, que fue anterior a que los dominicos se sirviesen de la encomienda como punto de apoyo, puesto que, como se ha visto, hay evidencias documentales y testimonios de la propia tradición dominica que presentan la vinculación entre la Mascarella y los navarros como ya existente al llegar santo Domingo.

\footnotetext{
4 D'AMATO, A., I domenicani e l'Universitd, pp. 27-30.

42 CAlzONI, F., Storia, p. 13; Annales Ordinis Praedicatorum, II, p. 466; D'AMATO, A., I domenicani el'Universita, p. 37.

43 D'AMATO, A., I domenicani e l'Universitd, p. 45; CAlzonI, F., Storia, p. 12.

44 D'AMATo, A., I domenicani e l'Università. p. 46, y SORBELLl, A., Notizie di professori e insegnamenti in Padova prima del 1222, «Studi e memorie per la storia dellUniversíta di Bologna», 7 , Bologna, 1922, pp. 117-128.
}

Sobre la Iglesia Medieval

Hispania Sacra 49 (1997) 
Lo cierto es que las dos instituciones no podían compartir indefinidamente la Mascarella, ya que ni la vida conventual de los dominicos podía desenvolverse allí con normalidad ni, por otro lado, su presencia permitía que la encomienda funcionase con arreglo a sus propios y múltiples fines. Algunos meses más tarde, cuando era ya imparable la difusión de la predicación de la nueva orden, se llegó a la separación, puesto que la Mascarella era en sí misma insuficiente para las necesidades universitarias que los dominicos convirtieron en el eje de su apostolado en Bolonia ${ }^{45}$.

El 6 de julio de 1221 los dominicos fundaron su convento boloñés llamado entonces de $\mathrm{S}$. Nicolò delle Vigne, destinado a ser un gran centro cultural, punto de reunión de los españoles en el siglo siguiente y meta de grandes peregrinaciones. La Orden de Predicadores no aspiró ni entonces ni nunca a la propiedad o la gestión de la Mascarella, que, pese a sus limitaciones, Ie había servido como puerta de entrada en la ciudad universitaria. Únicamente, y dirante siglos, ambas instituciones se disputaron las reliquias de santo Domingo que el hospital navarro siempre conservo, sus comendadores veneraron y la barbarie de los siglos destruyó mucho después de que Roncesvalles hubiese abandonado Bolonia ${ }^{46}$.

\section{LA PRIMERA ORGANIZACIÓN}

Las características de la comunidad de Santa María de Roncesvalles impusieron algunos signos específicos a la encomienda boloñesa. La Mascarella no es, para el hospital navarro, Sólo una encomienda local, sino que tiene algunas funciones sobre toda Italia, y los canónigos residentes en Bolonia como comendadores durante el siglo XIII son, a un tiempo, síndico, rector, administrador y comendador. Desde el punto de vista práctico, la diferencia entre la Mascarella y otras encomiendas se debe a que desde Bolonia se recaudaban limosnas y se organizaban cuestaciones en un ámbito mucho más extenso, reforzando así la importancia de los ingresos extraordinarios ${ }^{47}$.

Así como algunos de los títulos que los comendadores emplean en la documentación no pasan de ser meramente honoríficos, la extensión de su demarcación a toda Italia es, de este modo, una realidad efectiva con contenido económico ya a comienzos del 1200. En los estatutos de Roncesvalles de 1287, pero también antes de esa fecha, las funciones de comendador tienen claramente un doble sentido: de una parte están obligados a administrar los

45 CALZONL, F., Storia, p. 14.

46 Calzoni, F., Storia, p. 12.

47 Catálogo documental de Santa María Mascarella [Apendice], n. 11. 
bienes del hospital en su demarcación y a cumplir los fines a que aquellos estén adscritos; de otra, les corresponder organizar la recaudación de ingresos extraordinarios para enviar a Navarra. Hay algunos ejemplos de este segundo tipo de funciones en el caso de la Mascarella, donde los comendadores se arrogaron pronto plenas competencias sobre las limosnas obtenidas en Italia y Alemania ${ }^{48}$.

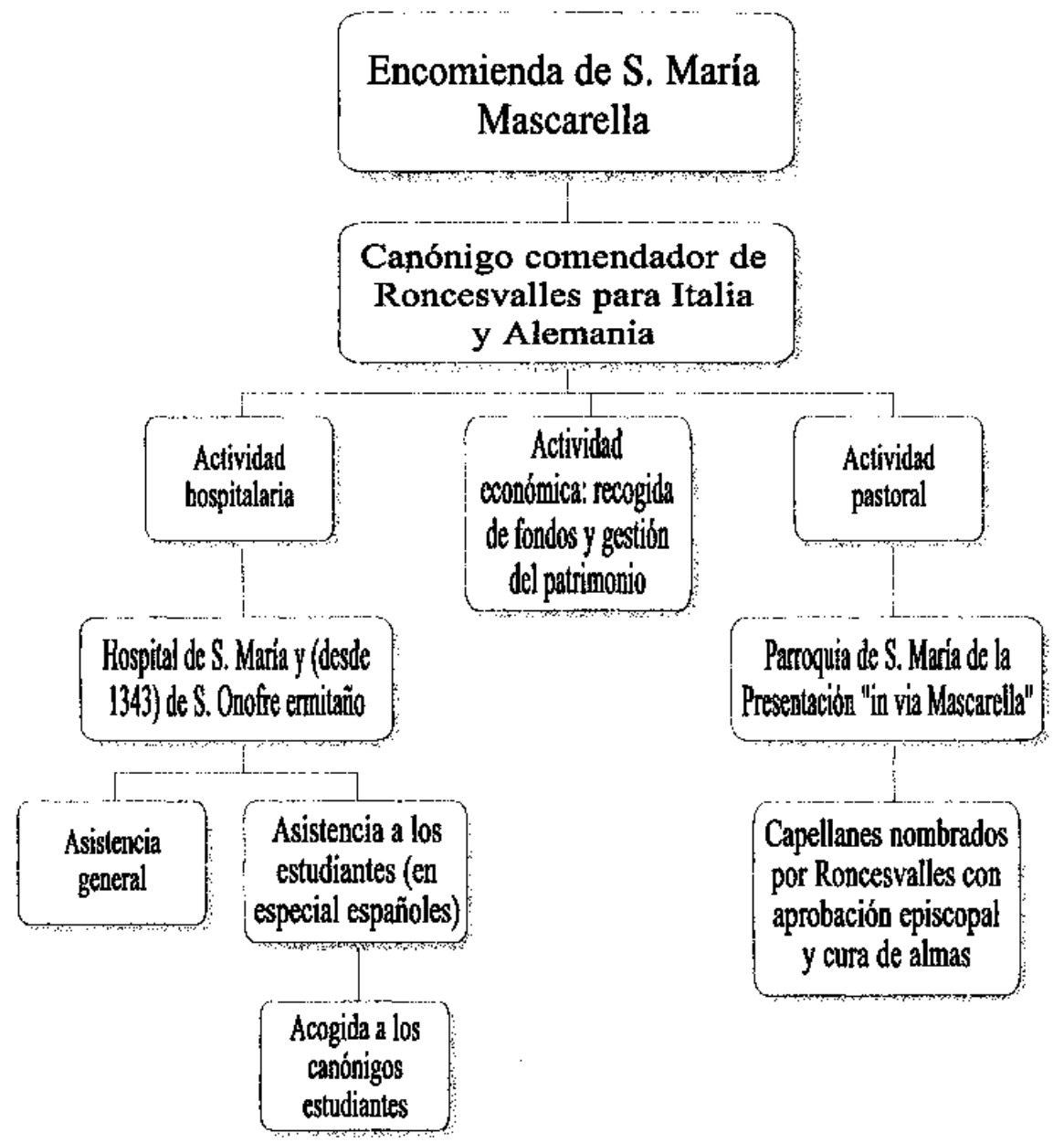

48 Catálogo documental de Santa María Mascarella [Apendice], n. 2. 
Considerando el conjunto de misiones de la encomienda. que hemos analizado más arriba, y la doble orientación de la figura del comendador, que acabamos de ver, no puede extrañar que una sola persona no bastase para dirigir la Mascarella y sus bienes y propiedades. Si a la administración del patrimonio (interior) unimos la captación de recursos exteriores, y si consideramos que, a la vez. el hospital tenía sus obras de caridad, alojaba escolares y gestionaba una parroquia (con cura de almas en la ciudad), comprenderemos fácilmente que se recurriese a personal auxiliar italiano y español. En particular, la actividad como hospital era muy conocida en la ciudad y le reportaba un indudable prestigio, también como reflejo de la tradición del hospital de Roncesvalles. Nos consta documentalmente que las atenciones a los necesitados fueron causa directa de algunas donaciones recibidas.

Si no es por una reputación ya consolidada, especialmente en el ámbito universitario y clerical, no se explicaría bien que los primeros dominicos, españoles y universitarios, se dirigiesen directamente a la Mascarella al legar a Bolonia, y no fueron los únicos que tomaron la encomienda como base inicial o permanente ${ }^{49}$. Los lazos entre la Mascarella y el Estudio fueron siempre estrechos entre 1200 y 1350, lo que no puede extrañar si pensamos, aparte de todo lo dicho, que la mayor parte de los canónigos comendadores parece haber realizado estudios completos o parciales en Italia. Ahora bien, si parece probado que una parte notable del esfuerzo asistencial se orientó a los estudiantes, esta vocación no fue excluyente, ya que, mediado el siglo XIII, se planeó la construcción de un segundo hospital, femenino y dependiente del primero. para lo que se obtuvieron abundantes donaciones y limosnas en Italia ${ }^{50}$.

Hemos recogido ya la opinión del doctor F. Miranda, que insinúa en varios momentos de su completo estudio que algunas de las encomiendas ultrapirenaicas de Roncesvalles tendrian una función predominantemente universitaria, lo que explicaría su localización. En este caso se hallarian algunas de las propiedades francesas, tal vez en parte las portuguesas, y casi seguramente no las británicas. Podemos concluir que esta orientación es evidente en la Mascarella, lo que se correspondería perfectamente con el probable origen de los bienes de Roncesvalles en Italia, intencionadamente comprados con tal fin y no recibidos casualmente por donación, como queda dicho; pero la Mascarella fue algo más.

La sola actividad asistencial y hospitalaria excedía con mucho las capacidades de gestión del canónigo-comendador, y esto sin recordar todas las otras tareas a las que nos acabamos de referir. Todos los comendadores, induso si

\footnotetext{
49 Catálogo decumental de Santa María Mascarella [Apéndice], n. 11; varios testigos, indudablemente estudiantes españoles, no son canónigos de Roncesvalles ni aparecen vinculados de ninguna manera al hospital navarro.

so Calzoni, F., Storia, p. 19.
} 
tenían el auxilio de otros navarros, recurrieron sistemáticamente a italianos, como auxiliares en el hospital y como capellanes en la parroquia. Aunque esta regla tuvo sus excepciones, es lógico que la cura de almas no se encomendase a españoles sino, en lo posible, a boloñeses, como se verá a continuación.

Aunque la parroquia-hospital que servía de centro a la encomienda fue claramente española hasta mediados del siglo XIV, y concretamente navarra, la mayor parte de los que allí trabajaron fueron siempre italianos. Aunque durante siglo y medio el comendador fue un canónigo español, se dejo cada vez más espacio a los italianos, clérigos o laicos. Al final, los capellanes italianos, especialmente, representaron la continuidad en una institución que de Roncesvalles sólo guardaba el recuerdo y que se hacía progresivamente secular. Ya en los años de crecimiento de la Mascarella este proceso, que culminó entre los siglos XIV y XVI, dio sus primeros pasos. Sin embargo, la misma complejidad de las misiones y de las circunstancias de la encomienda llevó a un resultado tan lejano de su propósito origínal.

El documento más antiguo conservado sobre la Mascarella, prescindiendo de referencias dudosas o indirectas, que hemos estudiado, es del 13 de enero de $1241^{51}$, y es de especial interés, ya que se refiere a la historia anterior de la institución. Como queda dicho al hablar del origen de la encomienda, en esta fecha se determinan, con arreglo a la documentación del siglo anterior (que se ha perdido), los límites parroquiales de la Mascarella frente a Santa María Magdalena de S. Donato. Rector de la misma y comendador era García de Roncesvalles, y capellán de la Mascarella el sacerdote italiano Angelo, probablemente bolonés. No sabemos si el comendador era estudiante en este momento, aunque es posible, ya que en estos años hubo varios civilistas españoles con el mismo nombre ${ }^{52}$.

El pleito con la parroquia limítrofe no tiene más importancia que la anecdótica. Ante un servicio fúnebre que una familia residente en la zona disputada pidió y obtuvo de la Mascarella, el vicario de la diócesis dio la razón a los rivales de los navarros, incluso si los vecinos afectados parecían inclinarse por

51 Catálogo documental de Santa María Mascarella [Apéndice], n. 1.

52 SARTI, M., y FATTORINI, M., De claris Archigymnasi Bononiensis Professoribus a saeculo XI usque ad saeculum XIV. Iterum ediderunt Caesar Albicinius (...) et Carolus Malagola. Tomus II, Bononiae, 1896, pp. 307 y ss. Tal vez el maestro G. López que fue prior de Roncesvalles en las décadas sucesivas, y que presidió la gran expansión de la institución bolontesa, pueda ser identificado con el primer comendador conocido de la Mascarella. En efecto, no sabemos en qué Estudio se formo; ahora bien, para aceptar esta hipótesis se le debería atribuir una longevidad poco común en la época; véase GoÑI GAZTAMBIDE, J., La formación, p. 194. n. 60; e IBARRA, J., Historia, p. 221. EI maestro G. López era prior en 1287, cuando fueron promulgados los nuevos estatutos (OSTOLAZA ELIZONDO, M. I., Colección, p. 393). 
ellos ${ }^{53}$. El documento nos muestra, pues, una institución en pleno funcionamiento, perfectamente arraigada en la ciudad y, desde luego, vinculada a Roncesvalles desde tiempo atrás (es decir, casi un siglo antes de lo que se ha considerado hasta ahora probado). La decisión arbitral nos recuerda un hecho con frecuencia olvidado, y es que, para todo lo relativo a la función pastoral en la ciudad (incluyendo el nombramiento de capellanes), la Mascarella dependió siempre de los sucesivos obispos, que no dejaron de servirse de estas prerrogativas para apropiarse de la encomienda y, en todo caso, intervenir en la vida interna de la misma.

A mediados del siglo XIII, sin embargo, el mejor momento de la Mascarella no había llegado todavía. Con casi un siglo de vida, a partir de 1270 aproximadamente, con un patrimonio suficiente fruto en parte de compras (presumiblemente) y de donaciones (con certeza), se conserva una serie bastante regular de documentos incluyendo los nombramientos de los comendadores, compras, ventas y grandes gastos en metálico, que demuestran la notable vitalidad de la fundación y permiten conocer mejor su funcionamiento interno.

El período mejor conocido de la vida de la Mascarella se inicia en 1267, con el establecimiento por el municipio de una tasa sobre los actos jurídicos documentados, que da lugar a que, como se ha dicho, queden regestos de todos los documentos de cierta importancia patrimonial (transmisiones por encima de 20 libras de valor). En 1268 se produce la compra, por parte del comendador Martín Jiménez (Martinus Eximinis), de un solar, probablemente un huerto, en el mismo barrio donde se hallaba la parroquia. A decir verdad, la noticia fue recogida en su momento por F. Guidicini, que la había encontrado en los archivos boloñeses, y ha sido repetida después por todos los autores. Esta compra es la evidencia de una situación financiera desahogada de la encomienda ${ }^{54}$. Martín Jiménez, el canónigo comendador, tuvo una larga estancia en Bolonia, muchos años después de dejar el cargo. Aunque no es éste el lugar de trazar su perfil biográfico, lo cierto es que era un canónigo de Roncesvalles que en 1269 terminó sus estudios y, en lugar de volver a Navarra, se estableció en Bolonia como profesor de Derecho civil y jurisconsulto, abandonando por lo que sabemos toda relación con la Mascarella y con Roncesvalles ${ }^{55}$. Su carrera universitaria y su patrimonio personal son excepcionales en la historia de la

53 CALZON, F., Storia, pp. 19-20, donde se describen detalladamente estos límites con referencia a la geografia urbana del siglo XVIII.

54 CALZONI, F., Storia, p. 22.

55 SARTI, M., y FATTORINI, M., De claris, II, p. 315, en 1276, p. 320, en 1281, p. 21, en 1282, y, como maestro, SART1, M., y FATTORIN1, M., De claris Archigymnasi Bononiensis Professoribus a saeculo XI usque ad saeculum XIV. Iterum ediderunt Caesar Albicinius (...) et Carolus Malagola. Tomus I, Bononiae, 1888, p. 483, sin confundirlo con el profesor de filosofia coetáneo y casi homónimo, ibidem, p. 593. 
Mascarella; seguramente fue enviado a Italia para que completase su formación canónica pero, al llegar la hora del retorno, prefirió asentarse en la ciudad como clérigo secular antes que volver al Pirineo. Su vida en Bolonia nada tuvo que ver con los avatares de la institución navarra ni con la trayectoria de la comunidad estudiantil española y al morir, en 1300 , ni sus herederos ni los testigos de su testamento fueron españoles.

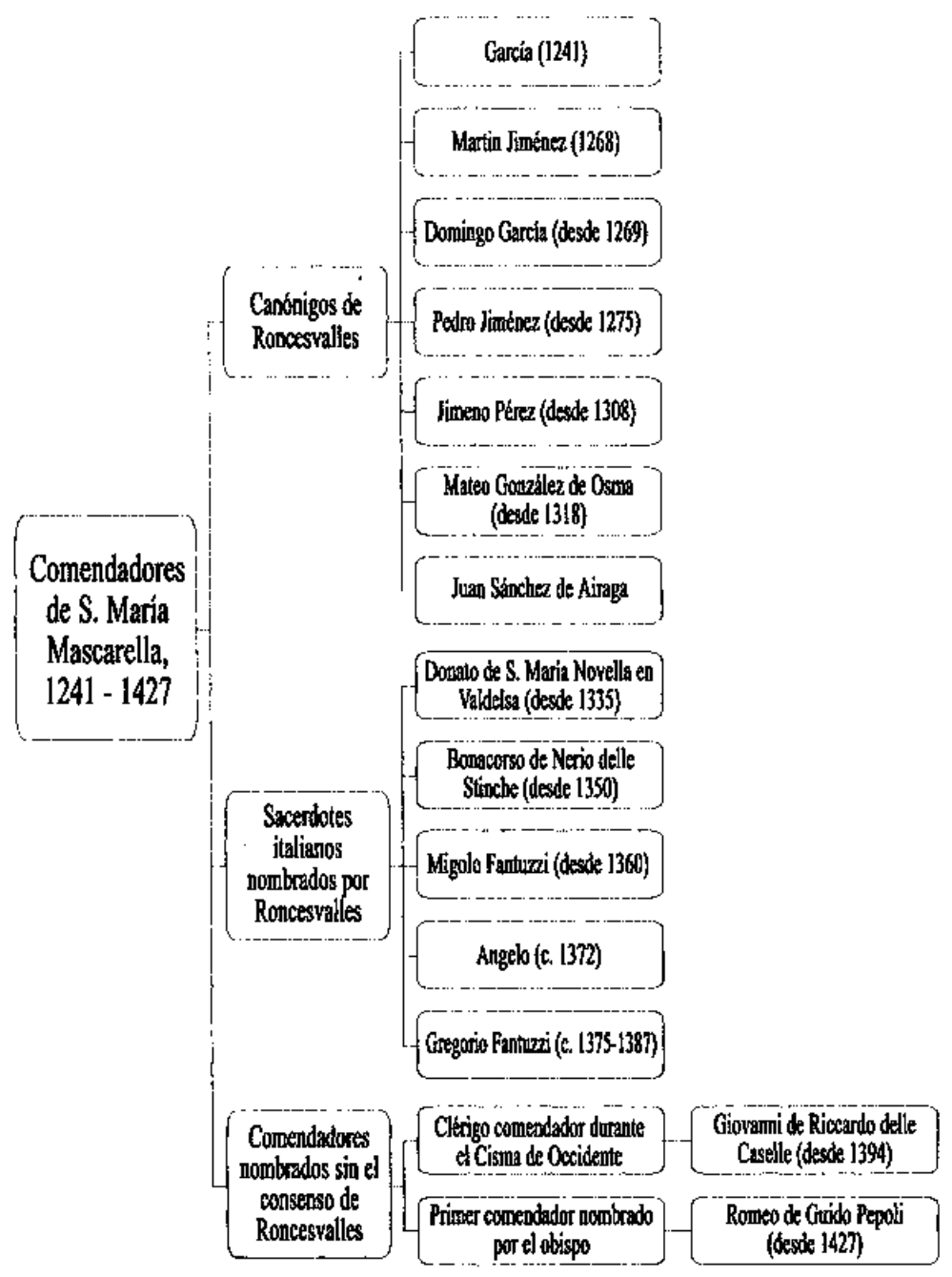

Sobre la Iglesia Medieval Hispania Sacra 49 (1997) 
Antes de licenciarse en la Universidad, el 5 de noviembre de 1268, Martín Jiménez recibió 80 libras boloñesas de Preso de Boninsegna, que a cambio fue autorizado a organizar cuestaciones en nombre de Roncesvalles en la Italia central y meridiona ${ }^{56}$. Dando en arriendo esta fuente de ingresos extraordinarios, los comendadores se encontraron, al menos en los momentos más florecientes, en condiciones de financiar todas sus obligaciones e, incluso, de enviar contribuciones significativas a Roncesvalles.

En un documento del 2 de enero de 1269 , el mismo $\mathrm{M}$. Jiménez devuelve una finca, de la que no se precisa la superficie, al madre de una joven. Esta propiedad, que era la dote de su hija, había sido entregada a la Mascarella en previsión de que ella profesase como religiosa en el hospital boloñés; al renunciar la interesada a esa posibilidad, su padre y tutor solicitó la devolución del depósito ${ }^{57}$. El hecho en sí no es importante, pero sí es significativo como síntoma de la actividad del hospital, en el que sin duda había otras muchachas. Según F. Calzoni, existía incluso una sección femenina del hospital, o más bien dos hospitales, lo que no deja de ser, al menos, dudoso ${ }^{58}$.

Poco después, y siempre en 1269, M. Jiménez dejó para siempre la Mascarella. A la encomienda debió lo esencial de su formación, sus excelentes relaciones en Bolonia y los comienzos de su brillante carrera docente y forense como civilista, que le proporcionó un apreciable patrimonio mueble e inmueble. La Mascarella, por su parte, se disponía también a vivir unas décadas de esplendor.

El 13 de mayo de 1269 Domingo García, otro canónigo de Roncesvalles, sucedió a Martín Jiménez en la encomienda ${ }^{59}$. Como sus predecesores García y Martín, era clérigo, y, como ellos, no tuvo la cura de almas de la parroquia de su pertinencia. Propuestos por el comendador, uno o varios sacerdotes italianos (por evidentes razones prácticas) eran nombrados por el Obispo de Bolonia como capellanes. En el plano económico y patrimonial, igualmente, su gestión fue de continuidad con las anteriores, hasta el punto que el único documento conservado sobre su tarea en la Mascarella fue la confirmación de una permuta de fincas planeada y realizada por Martín Jiménez ${ }^{60}$.

Los cambios de comendadores, sus idas y venidas de Roncesvalles y los consiguientes vacíos de poder en la encomienda eran un verdadero punto débil de la misma. Una disposición de Gregorio X en 1272, conservada en la Colegiata, ordena que los intereses de Roncesvalles en Bolonia sean defendidos, en

56 Catálogo documental de Santa María Mascarella [Ápendice], n. 2.

57 Cat́logo documental de Santa María Mascarella [Apéndice], n, 3.

58 Véase CAlzoni,.F., Storia, p. 18.

59 Catálogo documental de Santa María Mascarella [Apéndice], n. 4.

6 Catálogo documental de Santa María Mascareila [Apéndice], n, 5. 
ausencia del can6nigo comendador, por los benedictinos de S. Bartolomé61. Si se pensó en otorgar el amparo de una prestigiosa institución regular era, seguramente, porque la Mascarella había atraído el interés del clero secular y, como se vería a continuación, el de los propios obispos. Con el regreso definitivo a Navarra de Domingo Garcia, que tuvo lugar en 1275, se puede considerar terminado el período de nacimiento y consolidación de la encomienda, asentada en la realidad boloñesa y en condiciones de desarrollar autónomamente sus diversas misiones.

\section{EL SIGLO XIV: PROSPERIDAD Y DECADENCIA}

Pedro Jiménez, comendador al menos desde el 13 de diciembre de $1275^{62}$, tuvo, junto a las responsabilidades administrativas de sus predecesores, también la dirección espiritual de la parroquia, sustituyendo a los precedentes capellanes. Este cambio, probablemente debido a sus dotes personales y a las graves luchas que dividían a la ciudad aquellos años (con las lógicas dificultades para encontrar sacerdotes italianos adecuados ${ }^{63}$, marca el momento de máxima dependencia de Roncesvalles. En efecto, no sólo la dirección seguía siendo navarra, y también presumiblemente, como veremos, una parte de los beneficiarios de la asistencia hospitalaria, sino que también la parroquia fue gestionada directamente.

Si Pedro Jiménez pudo se encargado de la partoquia, fue porque conocía la ciudad y el romance italiano de la zona, además de ser, como canónigo de Roncesvalles, sacerdote. En efecto, en 1269 y 1270 nos encontramos con un Pedro Jiménez, capellán «de Burdeos», estudiante hispano de leyes ${ }^{64}$. Todo hace pensar, pues, que el comendador residía ya en la Mascarella desde hacía algún tiempo en el momento de su nombramiento, como era tal vez habitual.

Baste un dato para demostrar el profundo arraigo de Pedro Jiménez en la encomienda: nombrado en 1275 o quizás antes, su gestión se prolongó hasta 1308. Su caso es el opuesto al de Martín Jiménez, ya que, habiéndose quedado ambos en Bolonia, uno se dedicó a su carrera universitaria y el otro continuó como canónigo de Roncesvalles. Tras los problemas de gestión surgidos en la época de Domingo García, desde Roncesvalles se prefirió mantener en Italia un delegado permanente como defensor más eficaz de los intereses del hospital.

\footnotetext{
61 Catálogo documental de Santa María Mascarella [Apéndice]. n. 6.

62 Catálogo documental de Santa María Mascarella [Apéndice], n. 7, y CALZONI, F., Storia, p. 23.

${ }^{63}$ FASOLI, G., Bologna, pp. 150 y ss.

64 SARTI, M., y FATTORINI, M., De claris, II, pp. 310 y 312.
} 
Esta decisión era la preferida, precisamente, en los nuevos estatutos de Roncesvalles (aprobados, como se ha dicho, en 1287), que establecían que los comendadores demasiado alejados del núcleo navarro no participasen en la elección de prior. Así, los canónigos destinados a las encomiendas pasaban a adquirir un estatuto especial, diferente del propio de los canónigos de la Colegiata. $Y$ así, las necesidades operativas pasaron a tener mayor importancia que las tradiciones de la regla agustiniana, en el mismo momento en que tanto Roncesvalles como la Mascarella habían probado su madurez institucional ${ }^{65}$.

Durante la presencia de Pedro Jiménez en Bolonia como comendador tenemos noticias de otro canonigo, con certeza estudiante y muy probablemente residente en la Mascarella. Se trata de Guillermo Pérez de Roncesvalles (Guillelmus Petri de Rocha Vallis), que, según la monumental obra diciochesca de M. Sarti y M. Fattorini, estuvo en Bolonia en $1289^{66}$. Lamentablemente, no ha sido posible localizar el documento original, pero es indudable la identificación del personaje y su origen, así como muy plausible la hipótesis según la cual se habría alojado en la Mascarella.

Gestionado por italianos, el hospital continuaba, dentro de la encomienda, su actividad de beneficencia. Excepcionalmente se conserva el nombramiento de un encargado del hospital, hecho por Pedro Jiménez el 30 de noviembre de $1300^{67}$. Se trata del italiano Guido, hijo de Palmiero de Ladoça (Dozza, Imola), uno de los pocos subaltemos de la encomienda en toda su historia del que conocemos el nombre y la filiación. Aún así, es evidente que tuvo que haber desde tiempo atrás un cierto personal, siquiera mínimo, para mantener la iglesia y el hospital ${ }^{68}$. Tratándose de una profesión religiosa, en el caso que nos ocupa se registran todas las formalidades que vinculaban al personaje a la Mascarella.

Es interesante, para concluir, subrayar que, en el mismo documento de 1300 , Pedro Jiménez se titula «presbiter et sindicus et procurator hospitalis... in Italia et in Allamaniaw, ampliando así de hecho sus funciones a toda la Europa entonces católica al Oeste de las fronteras francesas. La importancia de esta novedad, aparte de en el prestigio, debe cifrarse en las limosnas y cuestaciones organizadas y subcontratadas.

65 Miranda, F., Roncesvalles, p. 97 y ss.

66 SART, M., y FATTORiN, M., De claris, II, p. 327.

67 Catálogo documental de Santa María Mascarella [Apéndice], n. 8.

68 Resulta tal vez demasiado precoz para esta fecha la descripción de la debilidad de Roncesvalles en Bolonia hecha por MiRANDA, F., Roncesvalles, p. 96. 


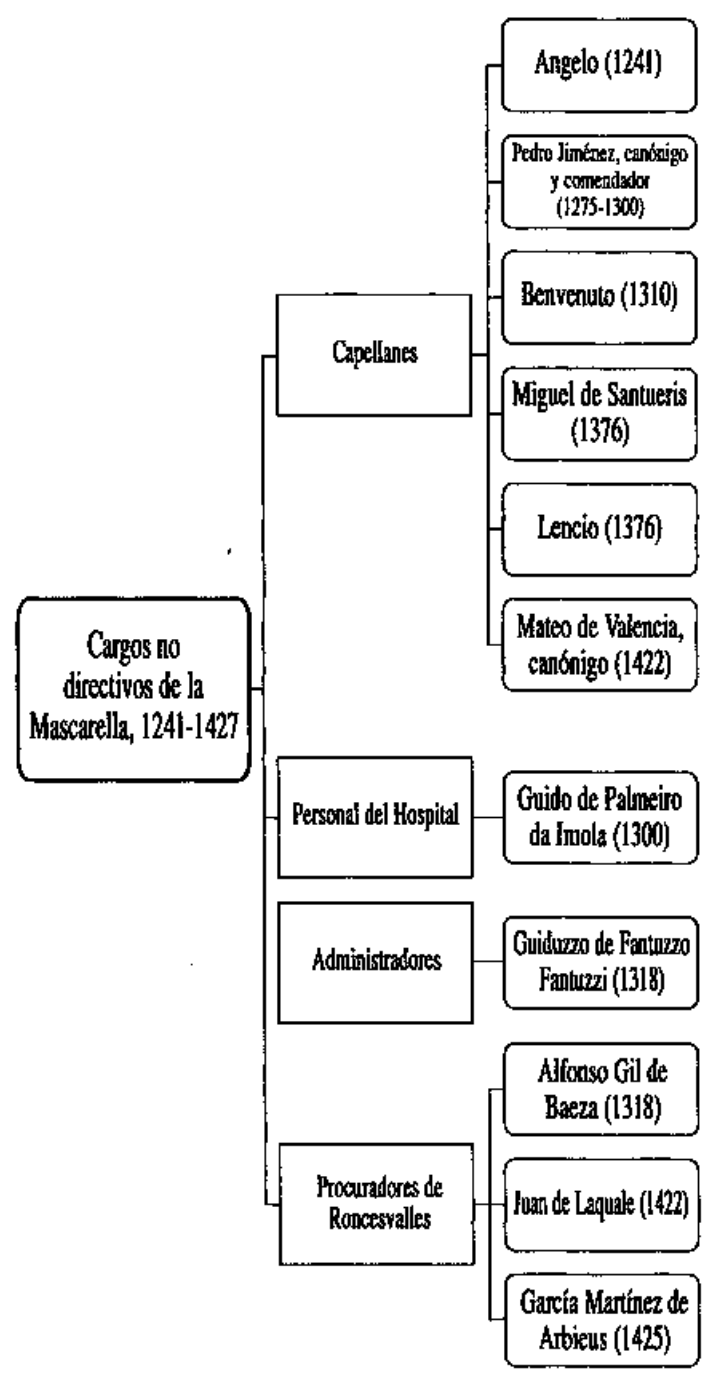

Después de una gestión muy prolongada, Pedro Jiménez dejó el puesto de comendador a Jimeno Pêrez, designado antes del 14 de septiembre de $1308^{69}$.

69 Catálogo documental de Santa María Mascarella [Apéndice], n. 9.

Sobre la lglesia Medieval

Hispania Sacra 49 (1997) 
Con seguridad, sabemos que el nuevo comendador no fue, a diferencia de su predecesor, capellán en la parroquia; no consta que Pedro Jiménez regresase a Roncesvalles, y bien pudo continuar durante cierto tiempo con esa parte de sus tareas en Bolonia. El 10 de septiembre de 1310 Jimeno Pérez, que llevaba ya dos años en Bolonia, vendió una casa y un huerto de la encomienda al boloñés Fulcerio Gislardi ${ }^{70}$. Esta venta es la primera señal conocida de una crisis económica en la Mascarella. En el propio documento se establece claramente que la venta de la casa se debió a una necesidad acuciante de dinero líquido para reconstruir el hospital (si bien no se conocen las causas de la ruina de éste). Entre los testigos del documento figura el capellán Benvenuto, presumiblemente italiano, y un cierto Francischus Dominici «de dicta capella» que podría ser un español.

El documento de 1310 es uno de los pocos que permiten entrever la naturaleza del patrimonio y de las rentas ordinarias de la Mascarella. Los datos son insuficientes para un intento de valoración cuantitativa. Parece que los bienes de la encomienda eran urbanos (casas dentro del recinto amurallado) y rústicos (fincas agrícolas). En ambos casos, de todos modos, los bienes eran alquilados para reducir los gastos y la complejidad de la gestión, y se concentraban en términos cercanos a la capilla-hospital. Pero lo característico de la estancia de Jimeno Pérez en Bolonia fueron más bien los gastos. El 2 de enero de $1318^{71}$ un procurador de Roncesvalles recibió de él 82 florines de oro, por orden directa del prior. El documento, en el que la Mascarella se nos presenta haciendo un esfuerzo económico extraordinario, tiene además la virtud de mostrar cómo se relacionaba el hospital navarro con su filial. Los canónigos confían sus órdenes a un viajero español, en este caso un estudiante, Alfonso Gil de Baeza, y le encargan que traiga a su regreso la cantidad solicitada, presumiblemente en los medios de pago de la época.

Este documento de 1318, por último, es interesante por el grupo de testigos que figuran en él. Por una parte, seis españoles, Accendo (?) Martínez de Aiesta [לde Ayesa?], Mateo González, Juan de Aragón, García Pérez de Olcoz, Pedro Ibáñez de Chirelghi (?) y Sancho Pérez de Caparroso, casi seguramente residentes en la Mascarella y, en algunos casos, destinados a desempeñar más tarde funciones de importancia dentro de ella. Indiscutiblemente, al menos García Pérez de $\mathrm{Olcoz}^{72}$ y Sancho de Caparroso eran navarros y habían llegado como canónigos o estudiantes de Roncesvalles. Por otra, Fantuzzo, hijo de

70 Catálogo documental de Santa María Mascarella [Apéndice], n. 10.

7 Catálogo documental de Santa María Mascarelja [Apéndice], n. 11.

72 Tal vez pueda identificarse como familiar del navarro Jimeno Pérez de Olcoz que el 27 de noviembre de 1306 había apelado al obispo de Pamplona contra los canónigos; véase GOÑI GAZTABIDE, J., Historia de los obispos de Pamplona, II, siglos XN-XV, Pamplona, 1979, p. 37. 
Guiduzzo Fantuzzi, miembro de una familia muy relacionada con la encomienda que, al final, terminaría por controlarla (tenemos aquí el primer documento de los muchos que relacionan a los Fantuzzi con la Mascarella). Un grupo relativamente numeroso de españoles, que representa en 1318 un presente dedicado a la Universidad y una función central para la «natio» hispana, junto a uno de los Fantuzzi, es decir, la solución italiana a los inminentes problemas del hospital.

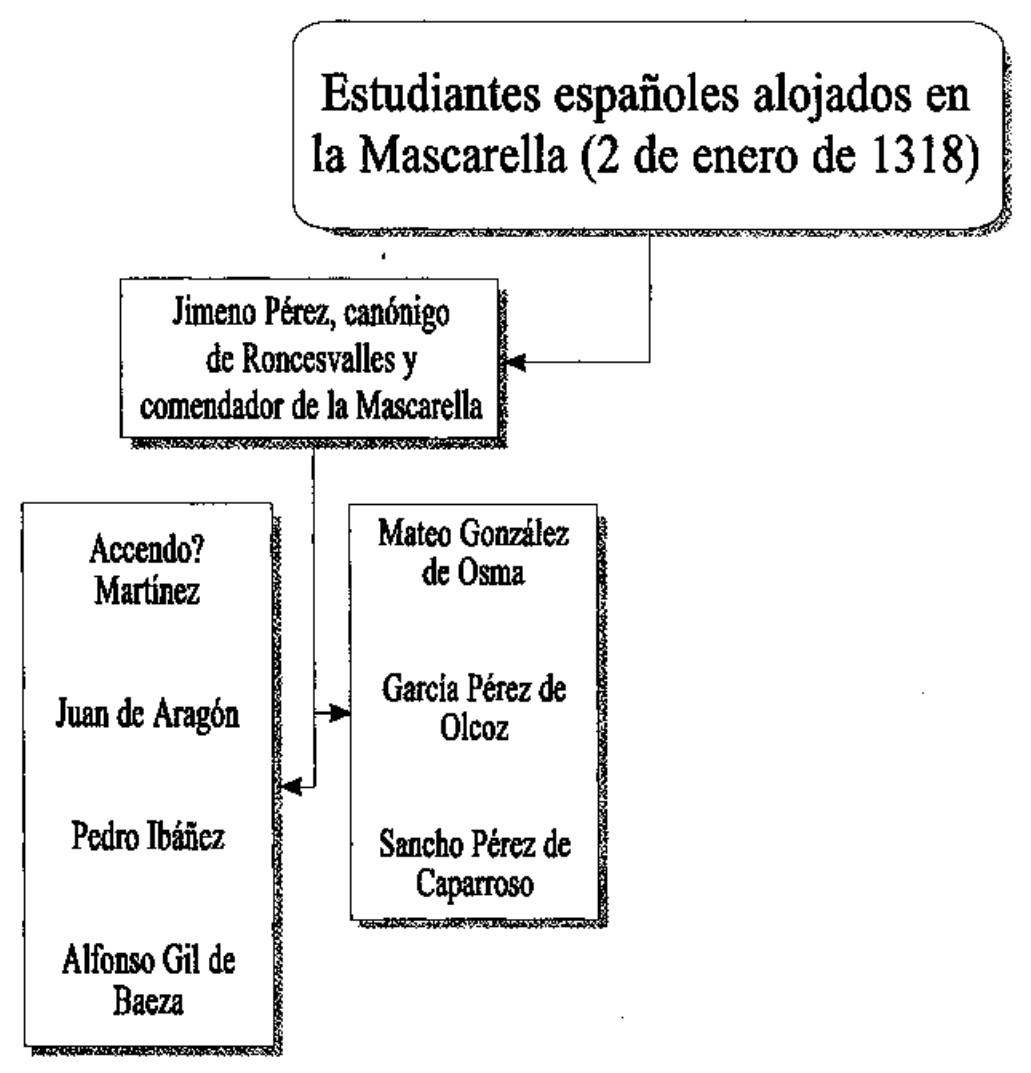

Uno de los españoles presentes junto al comendador Jimeno Pérez al inicio de 1318 fue nombrado a los pocos meses para sucederle. Mateo González de Osma, del que nos falta el documento de nombramiento, probablemente recibió instrucciones precisas sobre cómo gestionar la Mascarella, tal vez a través del propio Alfonso Gil de Baeza que había sido el portador del anterior men-

Sobre la Iglesia Medieval

Hispania Sacra 49 (1997) 
saje. Un cambio importante se cernía sobre la encomienda; el nuevo comendador procedió con rapidez a realizar las obras y reparaciones que desde hacía tiempo eran necesarias en la iglesia y en el hospital. Pero para cualquier inversión era necesaria una presencia constante en Bolonia, y los correspondientes avales y garantías, que los comendadores, en sus estancias generalmente breves en Italia no estaban en condiciones de obtener con facilidad. En estas necesidades está el origen del ascenso de los Fantuzzi, verdadera dinastía de gestores que representó durante bastante tiempo la continuidad de la Mascarella, y que, andando el tiempo, ocupó reiteradamente el puesto de comendador. En este sentido, el 11 de junio de 1318, el comendador Mateo González entregó 325 florines de oro a Guiduzzo, hijo de Fantuzzo Fantuzzi, probablemente para financiar obras de cierta importancia en la encomienda ${ }^{73}$. No se conoce el grado de parentesco entre este Guiduzzo y el Fantuzzo que hemos encontrado algunos meses antes.

El comendador González no consiguió que estos trabajos se empezasen, probablemente porque las posibilidades de financiación de la encomienda, a pesar de las gestiones de los Fantuzzi, no bastaban para ello. Cada vez más, en estos años, la Mascarella parece depender de recursos extraordinarios (limosnas $y$, sobre todo, herencias y legados testamentarios). En sus once años como comendador, Mateo González no consiguió gastar los 325 florines que había dado (¿como depósito?) a Fantuzzi, ya que por sí solos, al parecer, no eran suficientes para costear las inversiones previstas. El 17 de noviembre de $1329^{74}$ Juan Sánchez de Airaga fue nombrado comendador.

El 6 de junio de 1331 el nuevo comendador recuperó el depósito hecho por su predecesor, y con los 325 florines financió algunos trabajos en el hospital y en la iglesia aunque sin duda no con la envergadura planeada ${ }^{75}$. Una lápida del siglo XIV recordaba estos trabajos pero, respetada en la reconstrucción del siglo XVII, desapareció en el bombardeo del 25 de septiembre de 1943, y es conocida sólo por algunos dibujos ${ }^{76}$. Durante esta fase, los ingresos extraordinarios sirvieron sistemáticamente para hacer frente a gastos ordinarios; limosnas y donativos habían tenido siempre importancia en la economía de la Mascarella, pero para generar reservas o para remitirlos a Roncesvalles: la nueva situación implicaba una crisis permanente, que a la larga ponía en cuestion la independencia y la subsistencia de la encomienda como tal.

\footnotetext{
${ }^{73}$ Catálogo documental de Santa María Mascarella [Apéndice], n. 12; CAlzoNa,.F., Storia. p. 24.

${ }^{74}$ Catálogo documental de Santa María Mascarella [Apéndice], n. 13.

${ }^{75}$ Catálogo documental de Santa María Mascarella [Apendice], n. 14. Se trata de un documento con dos insertos, incluyendo el dep6sito original hecho por Mateo González y el nombramiento de Juan Sánchez como su sucesor.

${ }^{76}$ CALzon, F., Storia, p. 25.
} 
El 27 de agosto de 1333 la «Compagnia delle Laudi della $B$. Vergine», que se reunía en la Mascarella, recibió un pequeño legado en el testamento de Berta di Galvano ${ }^{77}$. En los años que siguieron, 1329-1335, se renovó la gestión económica de la encomienda, como en todas las posesiones de Roncesvalles apartadas del centro; la conclusión lógica de un proceso de racionalización del gasto era que desde Navarra se renunciase a la administración directa de la encomienda, asegurando unos ingresos y renunciando al complejo control de bienes tan lejanos y que, por lo que sabemos, habían perdido en buena parte su importancia cono nexo con la vida universitaria. En cierto sentido, la Mascarella, la propiedad más lejana, sirvió para ensayar un modelo de reforma que se aplicó al resto algunos años después ${ }^{78}$. Para Roncesvalles, en definitiva, era preferible manejar sumas más modestas pero desentenderse de una fuente continua de problemas y renunciar a dispersar a los canónigos por Europa en una política sin beneficios garantizados.

\section{LA ITALIANIZACIÓN}

La nueva filosofía en la gestión del patrimonio de Roncesvalles era, pues, el ahorro y la reducción de gastos; una de las primeras encomiendas en notar sus efectos fue precisamente la Mascarella. Sin embargo, no sabemos cuál fue el proceso exacto que se siguió para sustituir los comendadores españoles con italianos. Probablemente fue una decisión tomada tiempo atrás en Roncesvalles, a la vista de los resultados económicos, que se aplicó cuando legó el momento de sustituir a Juan Sánchez. Ciertamente, no faltaban precedentes de italianos en puestos de responsabilidad en el mismo hospital ${ }^{79}$.

Llegamos así a 1335, cuando encontramos a Donato de S. María Novella en Valdelsa como comendador en Bolonia ${ }^{80}$. Nacido en las cercanías de Florencia, no se conocen ni las causas de su llegada a Bolonia ni las de su nombramiento. Probablemente ya estaba relacionado con la encomienda o, por otro lado, fue recomendado por alguna autoridad (el Obispo). Como quiera que fuese, la gestión de la institución, en idénticas condiciones económicas a las anteriores, no cambió en absoluto. En 1343 comenzó una nueva reconstrucción del hospital, tal vez con las cuatrocientas libras que Bertoluccio, hijo Pietro Squarzapelle, había dejado a la Mascarella al morir el 11 de mayo de $1342^{81}$.

\footnotetext{
77 Catálogo documental de Santa María Mascarella [Apendice], n. 15.

${ }^{78}$ MIRANDA, F., Roncesvalles, p. 121 y ss.; la fecha de este cambio puede fijarse aproximadamente en 1370 .

79 CALZONI, F., Storia, p. 26

80 Catálogo documental de Santa María Mascarella [Apéndice], n. 16.

81 Catálogo documental de Santa María Mascarella [Apéndíce], n. 17.
} 
Progresivamente, la Mascarella pasaba a depender de sus ingresos extraordinarios, esto es, de la buena voluntad de los boloñeses. Tras estas obras, el hospital fue conocido como de $\mathrm{S}$. Onofre, sin que Roncesvalles interviniese para nada en el cambio ${ }^{82}$.

Del mismo modo que el proceso de italianización puede considerarse iniciado a finales del siglo XIII, es decir, mucho antes del nombramiento del primer comendador italiano, a mediados del siglo XIV se rastrean los síntomas de la tendencia paralela, aunque más tardía, de laicización. Al terminar la afluencia de canónigos navarros, no sólo se extinguía la presencia de españoles, sino también la de miembros del clero regular. Ciertamente, los comendadores siguientes tenían formalmente, según lo dispuesto por los estatutos de 1287, una cierta dependencia de Roncesvalles. Pero no participaban de ninguna manera en la vida de la comunidad, y seguían siendo, a todos los efectos, miembros del clero secular boloñés. Además, puesto que se seguían empleando capellanes para la parroquia, nada impedía que el comendador fuese un laico, como en efecto sucedió más tarde.

Desde 1350 fue comendador otro italiano, Bonacorso, hijo de Nerio delle Stinche, del que no se conocen otros datos ${ }^{83}$. Es una época de silencio sobre la presencia de estudiantes, y al declive de la presencia española en Bolonia y de la Mascarella se une la decadencia del mismo Estudio debilitado por las guerras en Italia y por el nacimiento de nuevas Universidades, en un período en el que, por lo demás, la gran Peste no favorecía especialmente ni los viajes ni las inquietudes científicas. Desde este momento, a la italianización y a la laicización se añade un tercer proceso evolutivo en la Mascarella, que podríamos llamar de progresiva separación del mundo universitario.

La familia Fantuzzi ya había colaborado con los comendadores españoles y, al nombrarse comendadores italianos, era lógico que el prior de Roncesvalles los eligiese entre los auxiliares tradicionales del hospital en Bolonia ${ }^{84}$. A los dos primeros comendadores italianos, de los que puede decirse muy poco, siguió en 1360 Migolo Fantuzzi ${ }^{85}$. A parte de su pertenencia a la familia Fantuzzi, aunque ni siquiera sabemos en qué grado de parentesco, su paso por la Mascarella resulta igualmente gris y vacío de información. De los Fantuzzi se puede intuir una notable habilidad para los propios negocios pero, Ígicamente, un cierto desinterés por los de Roncesvalles. Con el tiempo, parece que se establece un consenso tácito entre los Fantuzzi, por una parte, y el prior y los canónigos, por otra, según el cual Roncesvalles no intervendría en Bolonia a

82 GuIDICINI, G., Cose notabili, p. 201.

83 Catálogo documental de Sanła María Mascarella [Apéndice], n. 18.

84 Miranda García, F., Roncesvalles, p. 103.

Bs Catálogo documental de Santa Maria Mascarella [Apéndice], n. 19. 
cambio de recibir cantidades seguras aunque no muy grandes. Los peligros de esta tendencia son evidentes: la ausencia de los propietarios pondría en discusión el derecho de propiedad en cuanto surgiese una situación difícil. Los bienes de la encomienda, aunque escasos para justificar una gestión directa, eran sin embargo apetecibles y, por lo que después se vio, apetecidos.

El 20 de septiembre de 1365, Gandolfo de Riccardo Fantuzzi deja en su testamento un legado de 40 liras bolonesas a la Mascarella ${ }^{86}$, para que se pintasen ciertos frescos en honor de S. Onofre en el hospital de su nombre. El pío donativo muestra que la Mascarella era para los Fantuzzi algo muy parecido a una posesión.

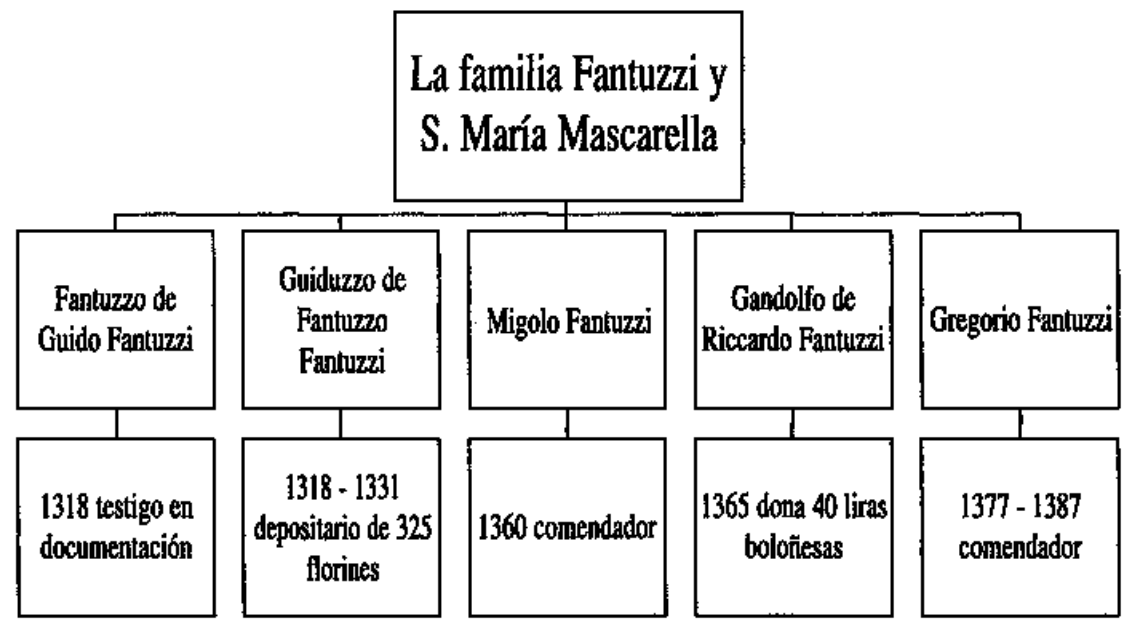

El comendador Angelo, conocido a través de un único documento, conservado en la Colegiata ${ }^{87}$, representa una posible interrupción en la hegemonía de los Fantuzzi y no ha dejado, extrañamente, ningún rastro en la documentación boloñesa, aunque no cabe un hipotético error en el documento español. El 4 de octubre de 1372 entregó 90 florines al hospital, como parte de un pago que se le había hecho. Ahora bien, si es cierto que no nos consta que este personaje fuese uno de los Fantuzzi, tampoco existen razones para no creer que se tratase de alguien vinculado a ellos, lo único que explicaría su nombramiento.

so Catálogo documental de Santa María Mascarella [Apéndice], n. 20.

87 Catálogo documental de Santa Maria Mascarella [Apéndice], n. 21; MARTINENA RuIZ, J. J., Catalogo, n. 292, p. 120. Interpretación del hecho en MIRANDA GARCiA, F., Roncesvalles, p. 123. 
El 16 de noviembre de $1376^{88}$ los parroquianos de la Mascarella pidieron por escrito al prior Sancho de Roncesvalles que un sacerdote de nombre Lencio sucediese al difunto fray Michele de Santueris como capelián. Tal vez la iniciativa de los fieles fue dirigida por los Fantuzzi para colocar a alguien cercano a ellos: en todo caso, en Roncesvalles parece no haber excesivo interés por el asunto, a pesar de ser este nombramiento un derecho importante al que después tuvo que recurrirse, en circunstancias bien distintas, para intentar recuperar la encomienda.

La mejor prueba de cuanto se lleva dicho sobre la continuidad de la presencia de los Fantuzzi es que, en 1377 y seguramente antes, otro miembro de la familia, de nombre Gregorio, era de nuevo comendador ${ }^{89}$. Hasta 1387 tenemos noticias de su presencia en la Mascarella, y con casi total seguridad él vivio como comendador el comienzo del Cisma de Occidente en 1378, sin sospechar el impacto decisivo que había de tener en la institución.

Es complejo realizar un balance de la gestión indirecta de la encomienda. Por su parte, los canónigos navarros se libraron del peso de una gestión directa que les obligaba a mantener permanentemente un canónigo en Bolonia para no obtener sino magros resultados económicos. Pero, por otro lado, eran muchos los riesgos de una permanente lejanía, como se vio más adelante. Ciertamente, el peso de la Mascarella en Roncesvalles, una vez casi anulado su papel cultural y formativo por el auge de las universidades francesas, era mínimo, pero tampoco había una voluntad de enajenar gratuitamente aquellos bienes y derechos.

\section{EL. CISMA DE OCCIDENTE Y LA CRISIS DEFINITIVA DE LA PRESENCIA NAVARRA EN BOLONIA}

Frente al Cisma, Bolonia y su Estudio adoptaron una misma postura, y ambas instituciones estaban condicionadas sobre todo por la necesidad de estabilidad política frente a una crisis que era a la vez institucional y política ${ }^{90}$. Obligada Bolonia a optar por el bando urbanista, Roncesvalles quedaba en la obediencia opuesta, como toda España. Mientras Gregorio Fantuzzi siguió al frente de la encomienda, el verdadero problema no afloró, ya que a nadie interesaba complicar aún más la situación. Sin embargo, en algún momento entre

88 Cat́lílogo documental de Santa María Mascarella [Apéndice], n. 22; MartiNENA RuIZ, J. J., Católogo, n. 317 , p. 129.

39 Catálogo documental de Santa Maria Mascarella [Apéndice], n. 23.

90 DE MATTEIS, M. C., Atteggiamento colto e posizione di Bolognia durante lo Scisma d"Occidente, en CAPTTANI, O., Cultura universitaria e poteri pubblici a Bologna dal XII al XV secolo. Alti del $2^{\circ}$ Convegno, Bologna, 20-21 Maggio 1988. A cura di..., Bologna, 1990, pp. 179-196. 
1387 y 1394 (no es posible precisar en qué momento exacto) falleció el comendador, dejando un vacío dificil de llenar. Ni la Curia episcopal ni la ciudad podían aceptar una designación que viniese de los clementistas de Roncesvalles, ante todo porque, desde su punto de vista, no habría sido canónicamente válida ${ }^{91}$. El patrimonio de la Mascarella seguía siendo apetecible y, por otro lado, no surgió a tiempo un candidato de la família Fantuzzi, como habría parecido lógico.

El hecho es que Giovanni, hijo de Riccardo delle Caselle, fue nombrado comendador por la Curia romana en 1394, en función de la situación de cisma respecto a Roncesvalles y sometiéndole a condiciones económicamente muy onerosas 92 . En efecto, Bonifacio IX le impuso una contribución de cien florines de oro sobre las rentas de la encomienda. Formalmente, los derechos de Roncesvalles se respetaron, y el nuevo comendador asumió formalmente los mismos signos distintivos que sus predecesores italianos. Pocas fueron, en realidad, las diferencias prácticas en Bolonia, pero había una gran novedad jurídica: gracias al Cisma, Roma se había hecho con el control último de la Mascarella $y$, fuerte como nunca lo había sido Roncesvalles, dificilmente iba a cederlo de nuevo.

Por orden de Roma, el nuevo comendador pagó la cantidad establecida a Bassotto, hijo de Isnardo de Argile, y con esto termina lo que sabemos de su gestión. Sólo después del fin del Cisma en 1417 Roncesvalles pudo empezar a pensar en un regreso a Bolonia, y para ello tendría que enfrentarse sucesivamente a la Curia, a la Iglesia boloñesa y a los titulares de la encomienda: demasiado para lo poco que la Mascarella podía representar económicamente.

\section{INTENTOS DE REGRESO A BOLONIA DE LOS CANÓNIGOS DE RONCESVALLES.} LOS DERECHOS SUBSISTENTES

Roncesvalles tuvo, después de 1417 , un momento de inacción respecto a la encomienda italiana, probablemente a causa de la debilidad de sus medios de presión en Bolonia. En aquellas circunstancias, no era posible plantear un ataque directo contra el comendador nombrado por Roma y sólo se podía $-\mathrm{y}$ aun esto con gran riesgo y escasos visos de éxito- intentar defender los derechos teóricos de propiedad; salvados los principios, sería posible recuperar el control directo de la Mascarella cuando llegase el momento de sustituir a Giovanni di Riccardo delle Caselle. La mayor dificultad para perseverar en esta política era, naturalmente, que en ningún caso la comunidad navarra estaba dis-

\footnotetext{
91 Calzoni, F, Storia, pp. 28-30.

92 Catálogo documental de Santa María Mascarella [Apéndice], n. 24.
} 
puesta a gastar para «reconquistar» el hospital más de lo que éste pudiese producir a corto plazo.

El primer paso que dio Roncesvalles fue un éxito relativo. En 1422 Juan de Laquale (¿Lacalle?), por procura de la Colegiata, consiguió que se aceptase a Mateo de Valencia como capellán de la Mascarella ${ }^{93}$. Este sacerdote era un canónigo de Roncesvalles, y su designación para un puesto en que normalmente se había confiado a un italiano era la manera más sencilla de volverse a introducir en la encomienda frente a las aspiraciones de las Curias romana y boloñesa. Más adelante, en 1425, Juan Galindo, prior de Roncesvalles, dio en arriendo las cuestaciones de la Mascarella en toda Italia a través de su procurador en Bolonja, Juan Martínez de Arbieus (¿Arbizu?). presumiblemente más como acto de posesión que por la cantidad obtenida ${ }^{94}$. En efecto, aunque no se había retomado la gestión directa, se estaban ejerciendo algunas de las funciones propias de los comendadores, preparando sin duda el terreno para el retorno a la normalidad institucional.

Pero el Papa decidió otra cosa. El 24 de marzo de 1427 Martín v nombró al laico boloñes Romeo, hijo de Guido Pepoli, como comendador, al tiempo que se secularizaba la encomienda. Parece que este Pepoli era ya administrador de hecho de los bienes de la Mascarella, al menos desde $1425^{95}$. Desde entonces, los comendadores habrían de ser seculares, como efectivamente sucedió hasta 1562 , cuando Roma dio la encomienda a la orden de los jesuatos, que la conservaron hasta su supresión en 1668. Posteriormente, ocuparon ła Mascarella los olivetanos de S. Michele in Bosco (asentados en Bolonia por voluntad de Gil de Albornoz) y, en el siglo XVIIl, la parroquia con todos sus bienes revirtió al Obispado ${ }^{96}$.

Poco podían hacer los de Roncesvalles ante la negativa pontificia. Convencidos de la imposibilidad de triunfo, los canónigos intentaron salvar lo salvable. Al fin y al cabo, durante demasiado tiempo la Mascarella sólo había ocasionado gastos y problemas, así que desde Navarra se obtuvo, en cada cambio que sufría la gestión de la encomienda, el derecho de alojar en ella a los canónigos que estuviesen en Italia. En esta extraña obstinación puede verse el recuerdo de la vieja función universitaria y formativa que la encomienda boloñesa había tenido en tiempos pretéritos.

\footnotetext{
9. Catálogo documental de Santa María Mascarella [Apendice], n. 25.

94 Catálogo documental de Santa María Mascarella [Apéndice], n. 26.

95 CALZONI, F., Storia, p. 31. Los documentos de esta transmision patrimonial se encontraban en 1785 en el Archivo de S. Michele in Bosco, la otra (re-)fundación del Cardenal Albornoz en Bolonia, además del Colegio que lleva su nombre; pero en la actualidad no ha sido posible encontrarlos.

\%6 GUIDICINI, G., Cose notabili, p. 201; DUINER, G., Geschichte der Jesuaten, Roma, 1975, p. 269: la cesión está fechada el 4 de julio de 1562, en nombre đe Pablo IV.
} 
En realidad, no sabemos si hubo efectivamente un ejercicio reiterado de ese derecho de alojamiento. Con seguridad, hubo canónigos que durmieron en Bolonia, pero con brevísimas estancias y sin la continuidad propia de posibles estudiantes. Por ejemplo, Juan de Lacarra, que viajó a Roma en octubre de 1437 como procurador de Roncesvalles, pasó por la Mascarella ${ }^{97}$. Del mismo modo, en 1532, el comendador Girolamo Fracassati cedió a la cofradía de Santa María Magdalena el hospital de la Mascarella y San Onofre, entonces en ruinas a cambio de que la cofradía se hiciese cargo de su obligacíon de hospedar a los de Roncesvalles ${ }^{98}$.

No se olvidó pronto ni fácilmente el origen navarro de la Mascarella, ni tampoco la función universítaria que indudablemente tuvo aquel hospital en la Edad Media. Mucho después de la desaparición de los canónigos de Roncesvalles de Bolonia, y precisamente en el momento en el que los jesuatos se hicieron cargo de la encomienda (1563), dos estudiantes españoles en Bolonia, Francisco Vivero y Juan Cabezón, escribieron al prior de Roncesvalles para instarle a recuperar la iglesia y el hospital. Se ha pensado en cuáles serían los intereses personales que les movieron a dar aquel paso, considerándolos estudiantes necesitados en Bolonia a la búsqueda de un alojamiento, y descartando decididamente que perteneciesen al Colegio de España (que, dicho sea de paso, jamás excluyó las candidaturas de navarros) ${ }^{99}$.

Hoy, sin embargo, puede demostrarse que ambos eran en aquel momento colegiales de la institución de don Gil de Albornoz, y tal vez se pueda incluso aventurar que su movimiento fue parte de un proyecto del Colegio de España, «heredero" moral del hospital navarto, para hacerse con los bienes de la encomienda y extender ulteriormente su papel de protección de todos los estudiantes españoles en Bolonia, fuesen o no colegiales. Juan Cabezón fue con certeza colegial porque, aunque no encontramos su nombre recogido en las listas al uso, fue testigo y garante en el juramento de otro colegial en 1561, y Francisco Vivero de Logroño, canonista y, por si fuese poco, capellán del Colegio (llegó a obispo de Calahorra), fue colegial desde enero de 1563 a marzo de $1569^{100}$.

${ }^{97}$ Catálogo documental de Santa María Mascarella [Apéndice], n. 27; y MARTINENA RUZz, J. J., Catálogo, n. 538, p. 207.

98 FORNASINI, G., La chiesa priorale, pp. 43 y ss. Catálogo docunental de Santa María Mascarella [Apéndice], $n .28$.

99 Ostolaza Elizondo, M. I, Colección, p. 30; y MiRanda García, F., Roncesvalles, p. 124, sobre la base de IBARRA, J., Historia, pp. 146-147.

100 PÉREZ MARTín, A., Proles Aegidiana, «Studia Alornotiana», XXXI, condiciones estatutarias de ingreso en el siglo XIV; vol. II, p. 912 sobre Juan Cabezón y vol II, p. 951 sobre Francisco Vivero.

Sobre la Iglesia Medieval

Hispania Sacra 49 (1997) 
No conviene olvidar que el prior de Roncesvalles era entonces (desde 1557 a 1575) Antonio Manrique de Lara de Valencia ${ }^{101}$, doctor en Bolonia y él mismo antiguo colegial del San Clemente. Este singular personaje, que con el tiempo fue obispo de Pamplona, no sólo debía conocer, tras ocho años de estancia, el pasado hispánico de la Mascarella, sino que debía estar muy al tanto de la confusa posición de los jesuatos y de la cofradía de S. Onofre. Nada más lógico, pues, que un proyecto por su parte que beneficiase tanto a la institución que regía como al Colegio que le había becado muy pocos años antes (de 1542 a 1551$)^{102}$. Aunque el intento no tuvo éxito y los dos colegiales no obtuvieron lo que deseaban, hay que recordar que Manrique de Lara fue, con toda probabilidad, el áltimo canónigo de Roncesvalles en adquirir la formación jurídica boloñesa que había distinguido durante siglos, gracias a la Mascarella, al hospital navarro, y que su proyecto enlaza las dos grandes instituciones españolas en la ciudad italiana.

\section{LA MASCARELLA: BALANCE DE UNA INSTTTUCIÓN PIONERA}

No se encuentran, ni en la documentación conservada ni en las obras consagradas a la Mascarella, datos absolutamente ciertos sobre su origen, su formación y la vinculación primera con Navarra. Sobre estos tres aspectos, hay elementos para suponer razonablemente, como queda dicho, que la parroquia y el hospital de Santa María en Bolonia se fundaron hacia 1200 o, como mucho, treinta años antes, que su origen fue puramente italiano y que Roncesvalles asumió casi inmediatamente la titularidad, bien por donación, bien por compra.

La institución y su patrimonio, cualquiera que fuese su origen, habían de servir, en la mente de los canónigos propietarios, a fines variados y, hasta cierto punto, contradictorios entre sí. Como todas las encomiendas de Roncesvalles, la de Bolonia tenía como meta la obtención de rentas suficientes, al menos, para autofinanciarse y para contribuir ocasionalmente a los gastos de la Colegiata. En segundo lugar, la Mascarella compartía con Roncesvalles -pero no con algunas otras encomiendas- una finalidad asistencial y caritativa a través del correspondiente hospital. Por último, la peculiaridad de la Mascarella fue su relación con la Universidad de Bolonia, y concretamente su importante papel cultural, al permitir el acceso de algunos canónigos a la cultura juridica italiana, sirviendo además como alojamiento para otros estudiantes españoles $y$, en algunas ocasiones, dando a la comunidad hispana un punto de referencia

101 Pérez Martín, A., Proles Aegidiana $I$, pp. 786-789.

102 IBARRA, J., Historia, p. 146. 
y una cierta cobertura institucional (como demuestra, entre otros, el caso de santo Domingo y sus discípulos).

Sin embargo, la Mascarella tuvo dos tipos de debilidades estructurales que, a la larga, hicieron imposible su subsistencia como tal. Ante todo, las derivadas de las contradicciones evidentes entre los múltiples objetivos que debía alcanzar. En otro orden de cosas, su confusa organización y su fragilidad financiera. Pasado su esplendor, Roncesvalles no podía permitirse gestionar directamente una encomienda tan lejana y tan frecuentemente deficitaria. Una vez iniciada, antes del siglo XIV, la fosilización del patrimonio boloñés, comenzó su progresiva degradación y desaparición bajo la administración de comendadores italianos que, de hecho, pronto se independizaron, para hacerlo de iure con ocasion del Cisma de Occidente.

Encomienda, parroquia, hospital, lugar de encuentro, la Mascarella sirvió de punto de apoyo a la participación española en el «modelo» universitario clásico de Bolonia, basado en las nationes y en el apoyo de los mendicantes en el momento de mayor afluencia de hispanos, y, al mismo tiempo, anticipó la única solución posible para la sucesiva crisis del mismo modelo. Éste, gestado en el siglo XII, estaba caracterizado a finales del XIII por el poder y la organización de las Universitates scholarium ${ }^{103}$. De las tensiones y conflictos del siglo anterior, de naturaleza penal y política, nació la agrupación de los estudiantes según su origen, fundamento de las peculiaridades del Estudio General; el progresivo reforzamiento, dentro y fuera de la institución universitaria, de los maestros y de los poderes públicos locales, impuso más tarde a los estudiantes su agrupación en instituciones colegiales más reducidas y sólidas, de las que la Mascarella fue la anticipación hasta el siglo XIV y el Colegio español de San Clemente la muestra más exitosa a partir de las mismas fechas ${ }^{104}$.

Menos numerosos que los hispani de otros orígenes, los navarros, estudiantes de Derecho sobre todo, pero también de otras disciplinas e incluso,

103 GreCI, R., L'associazionismo, p. 17, y BELloMo, M., Saggio, p. 57.

I04 MARTIN DE CASTRO, M., Españoles, portugueses e iberaamericanos en Bolonia, I, 1353 1499, Madrid, 1977, p. 10: el testamento del cardenal Albornoz (Archivo del Colegio de España en Bolonia, Codex Albornotianus,. IX, 1) dejo a su Colegio bienes suficientes para darle una independencia económica permanente, al tiempo que las reglas de los Estatutos están en su mayoría orientadas a garantizar la estabilidad de la fundación frente a los problemas que habian padecido otras instituciones universilarias. En sus imperfecciones, la Mascarella pudo ser un modelo para Gil de Albornoz al ordenar su fundación, ya que el Cardenal conoció sin duda la Mascarella en su decadencia. PÉrez Martín, A., Proles I, p. 16, sobre el mismo tema, BeneYTo Pérez, J., El Cardenal Albornoz. Canciller de Castilla y Caudillo de España, Madrid, 1950, pp. 333-346. Ademas, CuART MONER, B., Los Estatutos del Colegio de San Clemente como fuente para una aproximación al estudio de la burocracia, «Studia Albornotiana», XXXV, «El cardenal Albomoz y el Colegio de España», IV, Bolonia, 1979, pp. 579-69, especialmente pp. 585 y ss.

Sobre la Iglesia Medieval

Hispania Sacra 49 (1997) 
como se ha visto, maestros, estuvieron presentes en los centros de la vida universitaria medieval. Aunque el hospital-parroquia de Santa María «in via Mascarella» no tuvo un peso decisivo en la evolución patrimonial de Roncesvalles, su influencia intelectual fue central en la vida de la Navarra tardomedieval y demuestra la vitalidad cultural del reino, nunca aislado de las tendencias más actuales en cada momento, a uno y otro lado del Pirineo. 